\title{
Characterisation of a natural variant of the $\gamma$-butyrolactone signalling receptor
}

Marco Gottelt ${ }^{1,2}$, Andrew Hesketh ${ }^{3,4}$, Robert Bunet ${ }^{5}$, Pranav Puri ${ }^{1,6}$ and Eriko Takano ${ }^{1 *}$

\begin{abstract}
Background: The control of antibiotic production in Streptomyces coelicolor A3(2) involves complicated regulatory networks with multiple regulators controlling the expression of antibiotic biosynthetic pathways. One such regulatory network is that of the $\gamma$-butyrolactones, the so-called S. coelicolor butanolide (SCB) system. The Y-butyrolactones in this system serve as signalling molecules and bind to the receptor protein ScbR, releasing the repression of its target genes. The resulting expression changes affect the production of the two pigmented antibiotics Act and Red, as well as the transcription of the cpk antibiotic biosynthesis gene cluster and the synthesis of the $\gamma$-butyrolactones themselves.

Results: We identified a natural variant of ScbR in S. coelicolor (ScbR $\left.\mathrm{M600}_{0}\right)$ that differs from ScbR in the genome-sequenced strain M145 (ScbR $\left.\mathrm{M}_{\mathrm{M} 145}\right)$ by a single amino acid change, R120S. ScbR $\mathrm{R}_{\mathrm{M} 600}$ is impaired in its DNA binding ability and alters the expression of the pathway-specific regulatory genes of the red and cpk antibiotic biosynthesis gene clusters. Also, expression of the $\gamma$-butyrolactone biosynthesis gene $s c b A$ and production of the signalling molecules is slightly reduced.
\end{abstract}

Conclusions: The $\gamma$-butyrolactone receptor, ScbR, plays a key role in the SCB regulatory cascade and in determining the onset of the expression of the antibiotic regulatory genes.

Keywords: Gamma-butyrolactone receptor, Gene regulation, Antibiotic production, Streptomyces, ScbR, M600

\section{Background}

Streptomycetes show a complex morphological differentiation and produce a vast variety of secondary metabolites with great value in the pharmaceutical, chemical and agricultural industries [1,2]. The genome sequence of the model streptomycete Streptomyces coelicolor A3(2) strain M145, has been determined and is publicly available [3]. S. coelicolor A3(2) strains M145 and M600 are two of many strains independently derived from $S$. coelicolor A3(2). Both are prototrophic plasmid-free derivatives, but M145 was derived using both mutagenesis and recombination while creation of M600 did not involve any mutagenesis [4]. Genetically, M600 differs from M145 in that it possesses long terminal inverted repeats (TIRs) at both ends of the chromosome, resulting in the duplication of 1005 genes compared to M145.

\footnotetext{
* Correspondence: e.takano@rug.nl

'Department of Microbial Physiology, Groningen Biomolecular Sciences and Biotechnology Institute, University of Groningen, Nijenborgh 7, 9747 AG Groningen, The Netherlands

Full list of author information is available at the end of the article
}

This does not, however, appear to significantly affect total expression of the duplicated genes, since highly similar transcript levels could be observed when comparing the two strains [4].

In several Streptomyces species, small autoregulatory molecules called $\gamma$-butyrolactones are involved in controlling the onset of secondary metabolite production and morphological differentiation (reviewed in [5]). There are numerous diverse and complex regulatory systems involving $\gamma$-butyrolactones with the signalling cascade for A-factor in S. griseus being the best studied [6,7]. In S. coelicolor, $\gamma$-butyrolactones stimulating the production of Act and Red have been identified [8], together with the genes involved in $\gamma$-butyrolactone synthesis $(s c b A)$ and $\gamma$-butyrolactone binding $(s c b R)$. ScbR regulates transcription of both $s c b A$ and itself by binding to the divergent promoter region controlling both genes, and the $\gamma$-butyrolactone SCB1 inhibits this binding [9]. The regulatory influence of ScbR has been characterised by DNA microarray analysis, and a role in directly regulating a cryptic Type I polyketide biosynthetic gene 
cluster ( $c p k$ cluster) by binding to the promoter of its pathway-specific regulator $c p k O$ was identified $[10,11]$. We recently reported two metabolites derived from the hitherto orphan $c p k$ biosynthetic pathway, the yellow pigment yCPK and an antibiotic compound, abCPK [12]. ScbR does not, however, bind to the promoter regions of the pathway-specific regulatory genes for Act and Red synthesis [9], and it appears that SCB1 and scbAR do not regulate the production of these antibiotics directly. Nevertheless, an M145 $\Delta s c b R$ mutant (M752) is delayed in the production of Act and Red [9].

ScbR is a member of the TetR protein family [13], in which the Streptomyces $\gamma$-butyrolactone receptors show significant similarity to each other (30-40\% amino acid sequence identity). The crystal structure of a ScbR paralogue in S. coelicolor, $\mathrm{CprB}$, has been determined and is assumed to generally represent the structure of $\gamma$ butyrolactone receptors [14]. Active as homodimers, members of the TetR family bind to highly specific DNA binding sites in the promoter region of their target genes and typically repress their transcription. The regulatory region of the dimeric regulator contains one independent ligand binding pocket in each subunit. One $\gamma$ butyrolactone receptor thus binds two ligand molecules. Binding of $\gamma$-butyrolactones causes conformational changes and DNA binding is relieved [14].

In this study, the $S$. coelicolor $\gamma$-butyrolactone receptor ScbR in strain M600 ( $\left.\operatorname{ScbR}_{\mathrm{M} 600}\right)$ was found to differ from that in the sequenced strain M145 (ScbR $\left.\mathrm{M}_{\mathrm{M} 145}\right)$ by a single amino acid change. The effect of the M600type protein on the production of pigmented antibiotics Act Red, and the yellow compound, yCPK, as well as the $\gamma$-butyrolactones was assessed in vivo. In addition, the influence of SCBR ${ }_{\text {M600 }}$ on the expression of genes involved in the butanolide system and secondary metabolism was evaluated by quantitative real time PCR.
The effect onDNA and/or $\gamma$-butyrolactone binding ability of ScbR due to the amino acid substitution was also investigated in vivo and in vitro. Sequence analysis was used to determine the prevalence of the two forms of ScbR among strains of S. coelicolor and S. lividans. The $\mathrm{ScbR}_{\mathrm{M} 600}$ variant is present in only two, independent strains of $S$. coelicolor and its decreased DNA binding activity results in a delay in the transcription of the antibiotic regulatory genes.

\section{Results}

Two forms of the $\mathrm{\gamma}$-butyrolactone receptor ScbR in strains of S. coelicolor

2D gel-based proteomic analysis of transition phase liquid cultures from S. coelicolor strain M145 identified ScbR at a position consistent with its theoretical molecular weight and isoelectric point (spot 1 in Figure 1A). However, in an extensive analysis of strain M600 grown under the same conditions ScbR was never detected (data not shown). In an analysis of protein extracts prepared from spores of M600, ScbR was detected (spot 2 in Figure $1 \mathrm{~B}$ ) but at coordinates corresponding to a significantly more acidic isoelectric point compared to that observed in M145. This difference was confirmed by performing a separation of an equal mixture of the M600 spore extract and the M145 transition phase mycelial extract (Figure 1C), and indicates the occurrence of a modified form of ScbR in S. coelicolor strain M600.

\section{$\mathrm{ScbR}_{\mathrm{M} 600}$ from $S$. coelicolor M600 carries a single amino acid change, R120S, compared to $\mathrm{ScbR}_{\mathrm{M} 145}$ from strain M145}

To identify the M600 ScbR modification, the chymotryptic peptides detected for the ScbR proteins in M145 spot 1 and M600 spot 2 in Figure 1 were compared (Figure 2A,B,C, Additional file 1). Peptides corresponding

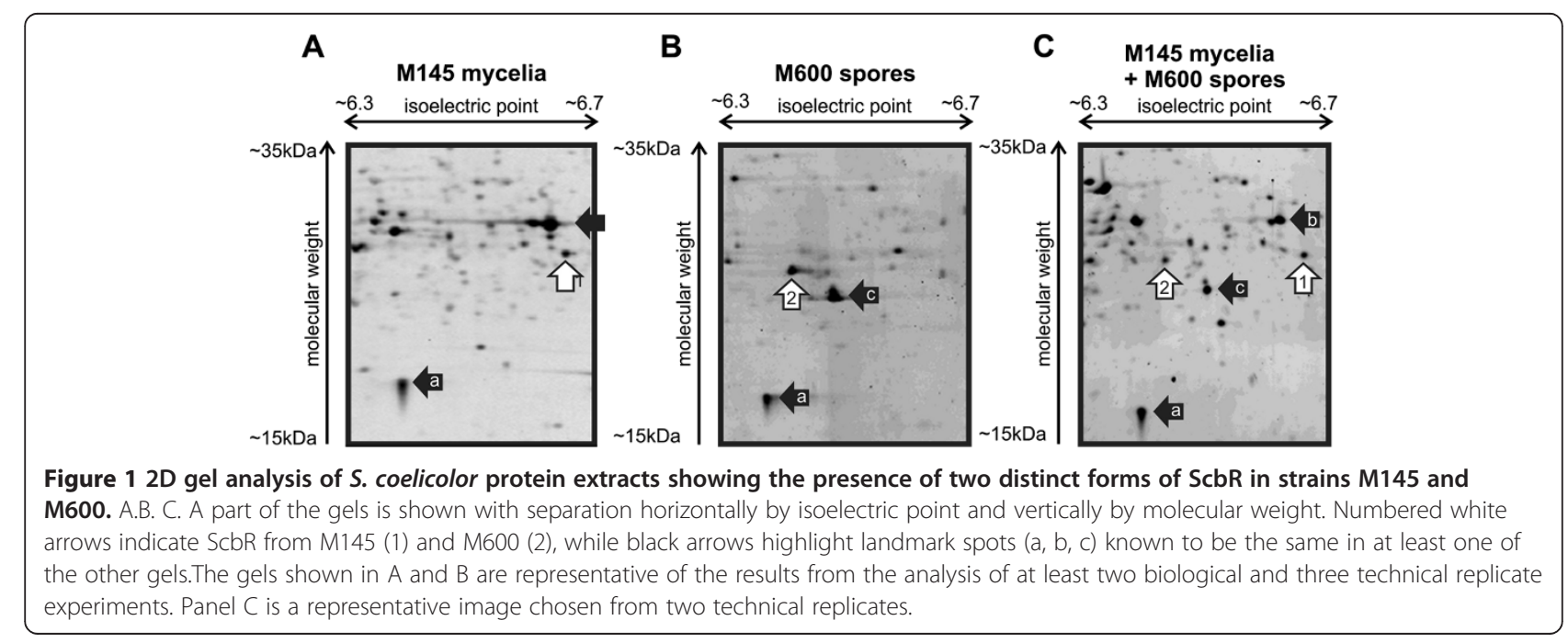


A

\section{MALDI-TOF of tryptic (and chymotryptic) digest}

\begin{tabular}{c|ccc} 
Spot & Matched peptides & Sequence coverage & MOWSE score \\
\hline 1 & $11(22)$ & $52 \%(87 \%)$ & $146(100)$ \\
2 & $7(21)$ & $39 \%(90 \%)$ & $88(103)$
\end{tabular}

B
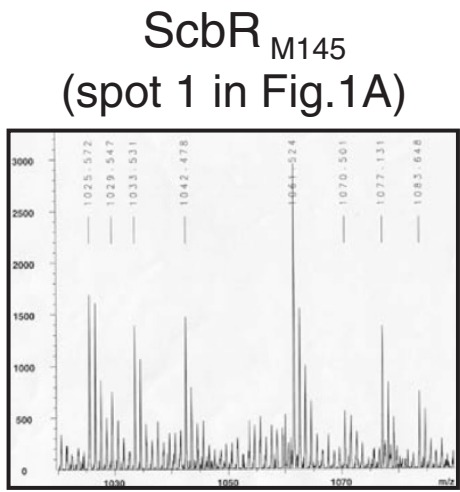

C<smiles>[AsH2]P[SeH2]</smiles>
(spot 2 in Fig. 1B)

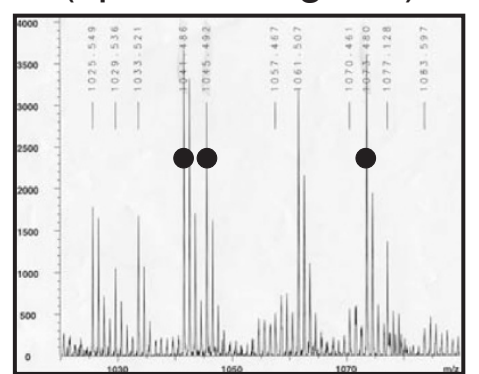

Figure 2 MALDI-TOF peptide mass fingerprint analysis of S. coelicolor strains M145 and M600 protein extracts. A. Identification of ScbR spots 1 and 2 by mass spectrometry after tryptic and chymotryptic digest. Data from the chymotryptic digests are given in brackets. B. C. Detail of the 1020 Da to 1090 Da mass range showing three extra peptides in ScbRM600 (spot 2 in A) (at 1041.486, 1045.492 and 1073.480 Da, marked with circles). The extra peak at 1041.486 Da was identified as RSWHETLL by Q-TOF mass spectrometry, and the other peaks are believed to correspond to the same peptide but with the tryptophan modified to kyneurenine (1045.492 Da) and formylkyneurenine (1073.480 Da).

to all the ScbR amino acid sequence except RRWHETLL and FHFQSKEELAL (indicated by black bars in Figure 3), were detected in the ScbR spot from M600 (Additional file 1). Peptides containing tryptophan can produce up to four peptide peaks in MALDI-TOF analysis due to two successive oxidations of the tryptophan residue (i.e. parent mass +16.0 Da and +32.0 Da), followed by spontaneous deformylation to kyneurenine (parent mass +4.0 Da) [15], and peaks at 1126.62 $\mathrm{Da}$ and 1142.62 $\mathrm{Da}$ in the data for the M145 spot correspond to the oxidised forms of the parent ion detected at 1110.62 Da. Interestingly, these three peptides are absent in the peptide mass fingerprint for the M600 ScbR spot, but three new peptide peaks apparently corresponding to a tryptophan-containing peptide can be detected at 1041.48 $\mathrm{Da}, 1045.49 \mathrm{Da}$ (parent +4.0 Da), and 1073.48 Da (parent +32.0 Da; Figure 2B,C). ScbR contains only one tryptophan residue, and the data therefore indicate that in M600 spot 2 ScbR has been modified on the RRWHETLL peptide resulting in a surprising mass loss of 69.09 Da (and an acidic shift in the isoelectric point value of the protein). This data correspond to the replacement of an arginine residue with a serine (69.069 Da). Analysis of the parent peptide ion at 1041.48 Da using Q-TOF mass spectrometry confirmed the sequence of this peptide as RSWHETLL (data not shown). This has also subsequently been verified via sequencing of the $s c b R$ gene in strain M600 (see below). The M600-type protein $\left(\mathrm{ScbR}_{\mathrm{M} 600}\right)$ therefore contains a single amino acid change (R120S) compared to the M145-type protein $\left(\mathrm{ScbR}_{\mathrm{M} 145}\right)$ (Figure 3$)$.

\section{$\mathrm{ScbR}_{\mathrm{M} 145}$ is the predominant form in S. coelicolor}

To survey the distribution of the dimorphism identified in ScbR, part of the $s c b R$ coding region of $16 \mathrm{~S}$. coelicolor strains was amplified by PCR using primers ScbRrt1 and ScbRrt2 and the sequence was determined. In addition, to confirm the $s c b R$ sequence in $S$. coelicolor M600 and S. lividans 1326, the entire scbR coding sequence and promoter region was amplified using primers ScbR2 and ETS10 (all primers used are listed in Additional file 2). ThescbR in M600, a single base pair change, c358a, was identified, confirming the amino acid mutation R120S observed in the proteomics analysis. The same mutation was also found in $S$. coelicolor strain $\mathrm{A}(3) 2 \mathrm{~N} 2$, but was absent in the other $14 \mathrm{~S}$. coelicolor strains tested, which all possessed the M145 genotype (Table 1). No other variants of $s c b R$ were observed in the strains tested. The $s c b R$ homologue in S. lividans differs from $s c b R_{\mathrm{M} 145}$ only by two silent point mutations, g402a and g582t. Thus, the S. lividans ScbR amino acid sequence is identical to that of $\mathrm{ScbR}_{\mathrm{M} 145}$. A multisequence alignment of the ScbR homologues are shown 


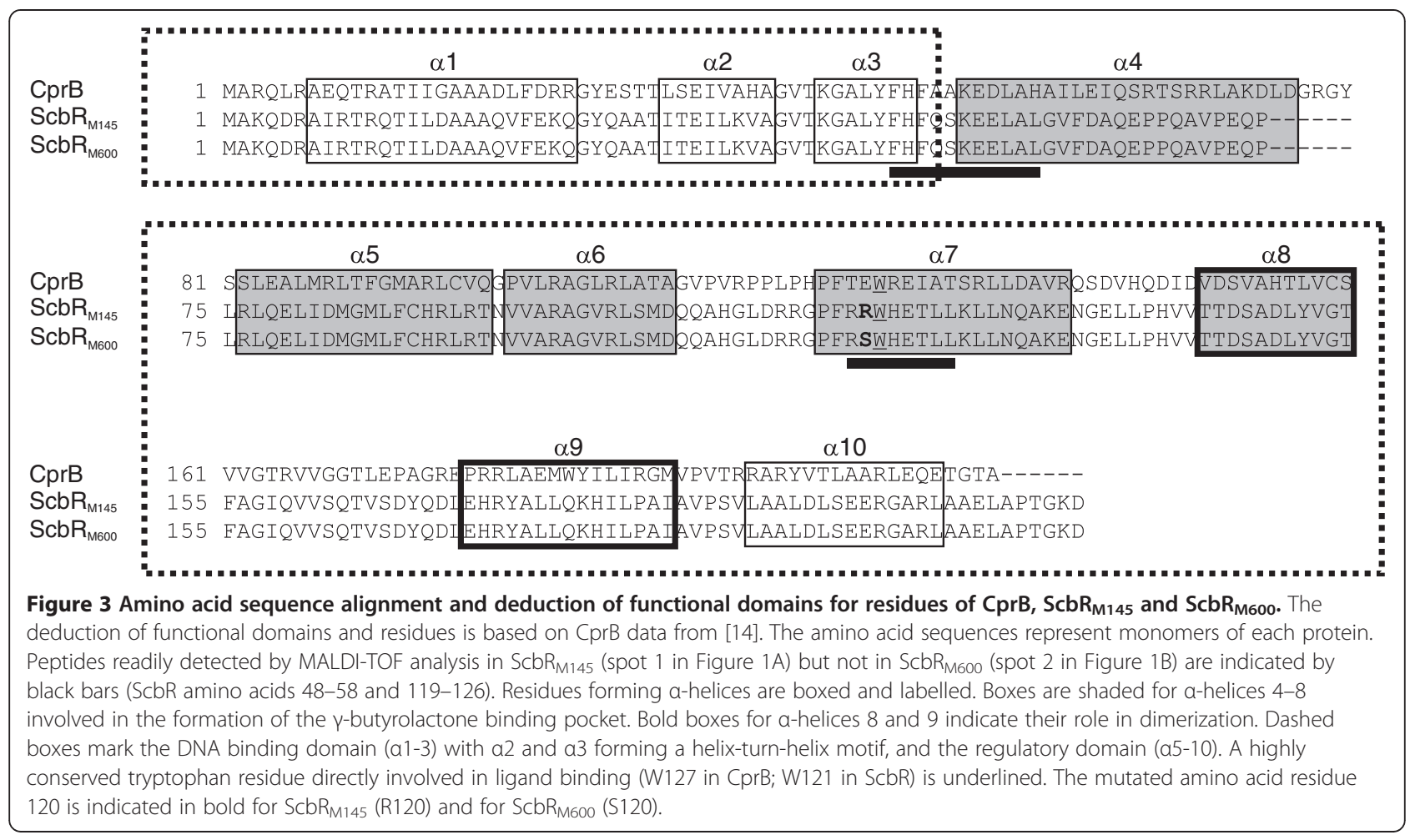

in Additional file 3. The $s c b R$ promoter regions from 251 bp upstream of $s c b R$, covering the ScbR binding sites of the intergenic region between divergently transcribed $s c b A$ and $s c b R$, are identical in S. coelicolor strains M145, M600 and also in the $s c b R$ homologue of S. lividans 1326 (data not shown). Our sequencing data were confirmed by the publicly available genome sequence of S. lividans (www.broadinstitute.org/annotation/genome/streptomyces_group/Regions.html).

\section{In vivo analysis of the $s c b R_{M 600}$ point mutation in a M145 background}

Production of pigmented antibiotics in strains M145 and M600 differ, with M600 being notably delayed in the onset of Act and Red biosynthesis, and this is comparable to the phenotypic change observed in strain M145 following deletion of $s c b R$ [9]. To determine whether the M600 phenotype may be attributed to the point mutation observed in $s c b R_{\mathrm{M} 600}$, a M145 ScbR deletion mutant was genetically complemented with constructs expressing either $s c b R_{\mathrm{M} 145}$ or $s c b R_{\mathrm{M} 600}$ under the native $s c b R$ promoter.

Plasmids pTE212 and pTE214 carrying $s c b R_{\mathrm{M} 600}$ and $s c b R_{\mathrm{M} 145}$, respectively, were used to replace the mutated $s c b R_{\mathrm{M} 145}$ locus in the M145 $\Delta s c b R_{\mathrm{M} 145}$ in-frame deletion mutant strain M752 [9] to give strains LW33 and LW34. LW33 therefore encodes $\operatorname{ScbR}_{M 600}$ in the M145 genetic background, and LW34 is the congenic control strain expressing $\mathrm{ScbR}_{\mathrm{M} 145}$. Correct construction of the strains was verified using PCR and Southern analysis (Figure 4A, B). Sequence analysis revealed a silent point mutation, c636t (leading to an "act" triplet instead of "acc", both resulting in Thr), in $s c b R_{\mathrm{M} 145}$ of strain LW34 (pTE214). Besides this mutation, strains LW33 and LW34 only differ by c358a in $s c b R$.

Strains LW33 and LW34 were grown in liquid SMM. Samples for RNA and protein isolation, as well as for $\gamma$ butyrolactone and antibiotic analysis, were collected at different phases of growth (Table 2).

\section{Antibiotic production in S. coelicolor LW34 and LW33 is comparable}

No difference could be determined for Act production. This was consistent between two independent growth experiments (Table 2). For Red, production increased 2fold in LW33 for GC 2 but the increase was not seen in GC 1 (Table 2).

We recently identified a yellow pigment (yCPK) and an antibiotic compound (abCPK) as metabolites of the hitherto orphan $c p k$ gene cluster [12] that may be the primary target of the $S$. coelicolor butanolide system. Therefore, in addition to Act and Red, we compared the production of the yellow compound in LW33 and LW34 grown on solid Difco Nutrient agar supplemented with glutamate where yCPK was found to be produced in high yields by the parental strain M145 [12]. The two tested strains showed no obvious difference in the production of all three pigmented secondary metabolites 
Table 1 Bacterial strains used in this study

\begin{tabular}{|c|c|c|c|}
\hline Name & Description & $s c b R$ type & Reference \\
\hline \multicolumn{4}{|c|}{ Escherichia coli } \\
\hline JM101 & 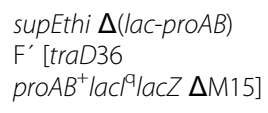 & - & [16] \\
\hline ET12567 & $\begin{array}{l}\text { Non-methylating } \\
\text { strain used for } \\
\text { conjugation with } \\
\text { Streptomyces }\end{array}$ & - & [17] \\
\hline
\end{tabular}

\section{Streptomyces coelicolor A3(2)}

\begin{tabular}{|c|c|c|c|}
\hline 11 & pheAl & $s c b R_{\mathrm{M} 145}$ & [4] \\
\hline 13 & uraAl & $s c b R_{M 145}$ & [4] \\
\hline 210 & ura-3 & $s c b R_{M 145}$ & {$[4]$} \\
\hline 290 & cys-4 & $s c b R_{M 145}$ & [4] \\
\hline 380 & glu-3 & $s c b R_{M 145}$ & [4] \\
\hline 05 & cysC3 & $s c b R_{M 145}$ & [4] \\
\hline 3(2) N1 & $\mathrm{A} 3(2)$ isolate & $s c b R_{M 145}$ & {$[4]$} \\
\hline $\mathrm{A} 3(2) \mathrm{N} 2$ & $\mathrm{~A} 3(2)$ isolate & $s c b R_{M 600}$ & [4] \\
\hline $3(2) N 3$ & $\mathrm{~A} 3(2)$ isolate & $s c b R_{M 145}$ & [4] \\
\hline A3(2)-Stanford & $\mathrm{A} 3(2)$ isolate & $s c b R_{M 145}$ & [4] \\
\hline $\mathrm{CH} 999$ & $\begin{array}{l}\text { proA1 argA1 redD60 } \\
\Delta \text { act::ermE SCP1- SCP2- }\end{array}$ & $s c b R_{M 145}$ & [4] \\
\hline 1501 & $\begin{array}{l}\text { hisA1 uraA1 strA1 } \\
\text { pgl-1 SCP1- SCP2 }\end{array}$ & $s c b R_{M 145}$ & {$[18]$} \\
\hline W33 & $\mathrm{M} 752+s c b R_{\mathrm{M} 600}$ & $s c b R_{M 600}$ & This study \\
\hline N34 & $\mathrm{M} 752+s c b R_{\mathrm{M} 145}$ & $s c b R_{M 145}$ & This study \\
\hline M132 & pheA1 SCP1- SCP2- & $s c b R_{M 145}$ & [4] \\
\hline 145 & $\mathrm{SCP} 1^{-} \mathrm{SCP} 2^{-}$ & $s c b R_{M 145}$ & [19] \\
\hline M600 & $\mathrm{SCP} 1^{-} \mathrm{SCP} 2^{-}$ & $s c b R_{\mathrm{M} 600}$ & [20] \\
\hline 752 & $\mathrm{M} 145 \Delta s c b R$ & - & [9] \\
\hline W3443 & wild type & $s c b R_{M 145}$ & [4] \\
\hline
\end{tabular}

\section{Streptomyces lividans}

1326 wild type $s c b R_{M 145}$ homologue [18]

during ten days of growth (Figure 5). From all these data there seems to be no significant difference in antibiotic production between LW33 and LW34 under the conditions tested, demonstrating that the difference in ScbR isoform does not explain the phenotypic difference of M145 and M600.

\section{$\mathrm{Y}$-butyrolactone production is slightly delayed in LW33}

$\gamma$-butyrolactone production of S. coelicolor strains LW34 and LW33 was determined using a kanamycin bioassay [21] at different phases of growth (Table 2, GC 2) corresponding to the sampling time points in the transcription analysis. Kanamycin resistance of a Streptomyces indicator strain is induced by the presence of $\gamma$ -
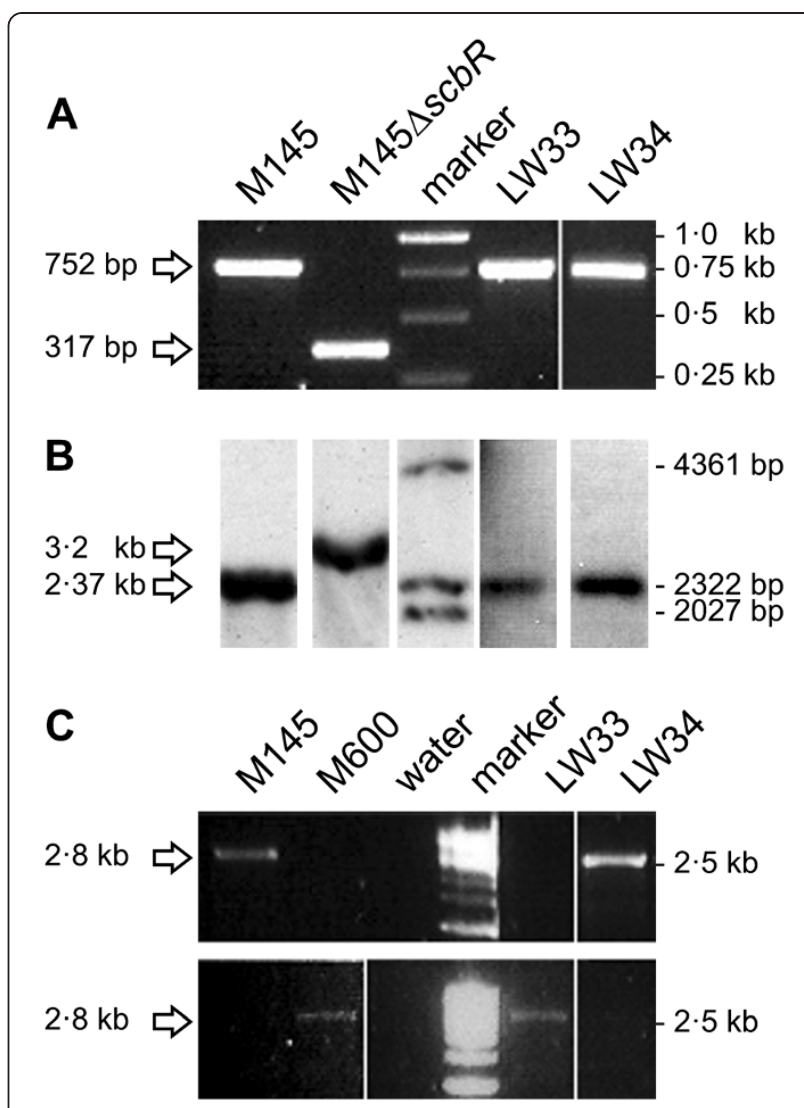

Figure 4 Verification of full-length $s c b R_{\mathrm{M} 145 / \mathrm{M} 600}$ in S. coelicolor strains LW34 and LW33. A. PCR was carried out using primers ETseq3 and ETS7 to amplify a 752 bp full-length $s c b R_{\text {M145/M600 }}$ fragment and a $317 \mathrm{bp}$ fragment from the $\Delta s c b R$ region. The $317 \mathrm{bp}$ PCR product was only found with the LW33/LW34 parental M145 $\Delta s c b R$ mutant. A full-length $s c b R_{M 145 / M 600}$ fragment was amplified from a wt control (M145) and from LW33 and LW34. Obtained PCR products are indicated with arrows on the left; sizes of the marker bands are given on the right. The M145-/M600-type of the gene was confirmed by DNA sequence analysis (data not shown). B. Southern analysis was carried out using Ncol digested genomic DNA of the four strains. A DIG-labelled DNA probe was used to detect the expected $3.2 \mathrm{~kb}$ fragment with M145 $\Delta s c b R$ and $2.37 \mathrm{~kb}$ fragments with the wt control (M145) and LW33 and LW34. Detected DNA fragments are indicated with arrows on the left; sizes of the marker bands are given on the right. C. PCR was carried out using primers RCseq31 and scbR-M145_c358 (scbR-M600_c358a) to amplify a $2.8 \mathrm{~kb} s c b R_{\mathrm{M} 145}\left(s c b R_{\mathrm{M} 600}\right)$ fragment. The latter are specific for the base change between the two $s c b R$ variants. $A s c b R_{M 145}$ fragment was only obtained with control strain M145 and with LW34, whereas control strain M600 and LW33 showed a scbR $R_{\text {M600 }}$ specific PCR product. Using water as template did not give any product. Obtained PCR products are labelled with arrows on the left; a $2.5 \mathrm{~kb}$ marker band is indicated on the right.

butyrolactones in extracts from the tested strains, and the extent of growth of the indicator strain on media containing kanamycin reflects the amount of $\gamma$ butyrolactones produced [21]. Extracts from stationary phase cultures of LW33 and LW34 produced similar 
Table 2 Growth and antibiotic production of LW34 and LW33

\begin{tabular}{|c|c|c|c|c|c|c|c|c|c|}
\hline \multirow{2}{*}{ time point } & & \multicolumn{4}{|c|}{ Growth Curve 1 (GC 1) } & \multicolumn{4}{|c|}{ Growth Curve 2 (GC 2) } \\
\hline & & \multirow{2}{*}{$\frac{1}{\mathrm{eT}}$} & \multirow{2}{*}{$\frac{2}{\mathrm{mT}}$} & \multirow{2}{*}{$\frac{3}{\text { IT }}$} & \multirow{2}{*}{$\frac{4}{5}$} & \multirow{2}{*}{$\begin{array}{l}\overline{1} \\
\mathrm{eT}\end{array}$} & \multirow{2}{*}{$\frac{2}{\mathrm{mT}}$} & \multirow{2}{*}{$\frac{3}{\text { IT }}$} & \multirow{2}{*}{$\frac{4}{S}$} \\
\hline growth phase & & & & & & & & & \\
\hline \multirow[t]{2}{*}{$\mathrm{OD}_{450}$ (hours) } & LW34 & $1.00(21)$ & $1.21(23)$ & $1.26(24.5)$ & $1.45(43)$ & $1.25(18)$ & $1.49(20)$ & $1.62(22)$ & $1.92(40)$ \\
\hline & LW33 & $1.04(21)$ & $1.18(23)$ & $1.25(24.5)$ & $1.42(43)$ & $1.56(18)$ & $1.38(20)$ & $1.58(21 \cdot 5)$ & $1.23(40)$ \\
\hline \multirow[t]{2}{*}{ Red } & LW34 & 0.3 & 0.6 & 0.9 & 3.9 & 0.1 & 0.2 & 0.6 & 0.7 \\
\hline & LW33 & 0.5 & 0.7 & 1.0 & 3.7 & 0.0 & 0.2 & 1.1 & 2.1 \\
\hline \multirow[t]{2}{*}{ Act } & LW34 & 0.0 & 0.0 & 0.0 & 1.0 & 0.2 & 0.1 & 0.1 & 0.5 \\
\hline & LW33 & 0.0 & 0.0 & 0.0 & 1.0 & 0.1 & 0.1 & 0.1 & 0.7 \\
\hline
\end{tabular}

S. coelicolor LW34 and LW33 were grown in duplo in liquid SMM (growth curves (GC) 1 and 2). Samples were taken at different phases of growth (early, mid and

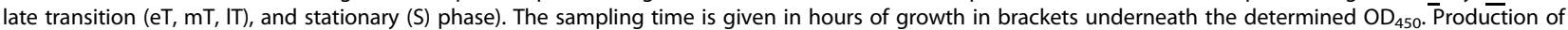
actinorhodin (Act) and (undecȳ-) prodiginines (Red) is given in $\mu \mathrm{g} / \mathrm{dry}$ cell weight $\mathrm{mg}^{-1}$.

halos of growth, indicating the presence of similar levels of $\gamma$-butyrolactones. Slightly higher levels were detected with mid and late transition phase samples in strain LW34 (Figure 6). This would indicate that $\mathrm{ScbR}_{\mathrm{M} 600}$ in strain LW33 leads to a minor reduction and delay in $\gamma$ butyrolactone production compared to LW34, and is consistent with the delay in $s c b A$ transcription observed in LW33 as shown below (Figure 7).

\section{Expression of $s c b R, s c b A$, redD and $c p k O$ is altered in strain LW33 containing the mutant $\mathrm{ScbR}_{\mathrm{M} 600}$}

Quantitative real time PCR (qRT-PCR) was used to measure the expression levels of the pathway-specific regulators of the act (actII-ORF4), red (redD) and the cpk ( cpkO) antibiotic biosynthesis gene clusters, and of $s c b A$ and $s c b R$ of the $S$. coelicolor butanolide system in the presence of the two forms of ScbR (Figure 7). Compared to the control strain LW34, redD expression was 2.5-fold lower at mid transition phase (mT) in LW33 harbouring the $\mathrm{ScbR}_{\mathrm{M} 600}$. RedD expression did not change dramatically from mid transition to late transition phase in LW33, while in LW34, the expression dramatically decreased. This resulted in a $>2$-fold higherredD expression in LW33 compared to LW34 at late transition phase. For GC 2, The onset of actIIORF4 transcription was delayed in LW33 but this was not observed in GC 1. Expression of $c p k O$ was only transcribed in late transition phase (IT), and thus later than in LW34. Also, the onset of scbAtranscription was delayed in LW33 and shifted from mid to late transition. Also with $s c b R$, maximum expression was reached only at late transition phase in LW33 compared to mid transition phase in LW34 (Figure 7 and Additional file $4 \mathrm{AB}$ ).

\section{$\mathrm{ScbR}_{\mathrm{M} 600}$ from Streptomyces shows reduced ability to bind to the $s c b R$ promoter sequence}

Cell-free extracts $(C E)$ of LW34 $\left(s c b R_{M 145}\right)$ and LW33 $\left(s c b R_{\mathrm{M} 600}\right)$ were prepared from samples taken at different phases of growth (Table 2) corresponding to the sampling time points in the transcription analysis. DNA binding ability was determined in gel retardation assays using a digoxygenin-labelled $s c b R$ promoter fragment containing the ScbR binding site upstream of its own promoter [9] and freshly prepared protein extracts (Figure 8A; shown for GC 1). Equivalent amounts of total protein used for the gel retardation analysis were also analysed by Western hybridization using an antibody to ScbR to determine the relative abundance of ScbR in the extracts (Figure 8B). Extracts from LW34 from late transition and stationary phase completely shifted the operator DNA in the binding assay (Figure 8A). This is consistent with the appearance of ScbR as detected by Western blotting (Figure 8B). In

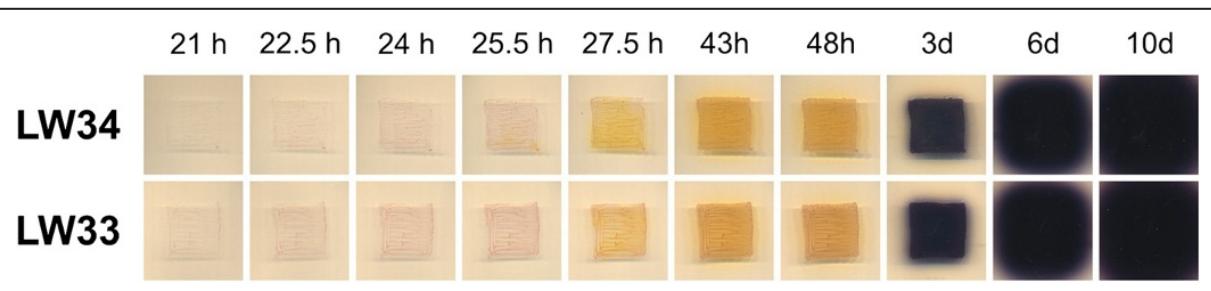

Figure 5 Secondary metabolite production in solid culture. S. coelicolor strains LW34 (scb $R_{M 145}$ ) and LW33 (scb $R_{\mathrm{M} 600}$ ) were incubated on glutamate-supplemented Difco Nutrient agar at $30^{\circ} \mathrm{C}$. Production of pigmented secondary metabolites was followed at 21, 22.5, 24, 25.5, 27.5, 43, $48 \mathrm{~h}$ and 3, 6, 10 days. 


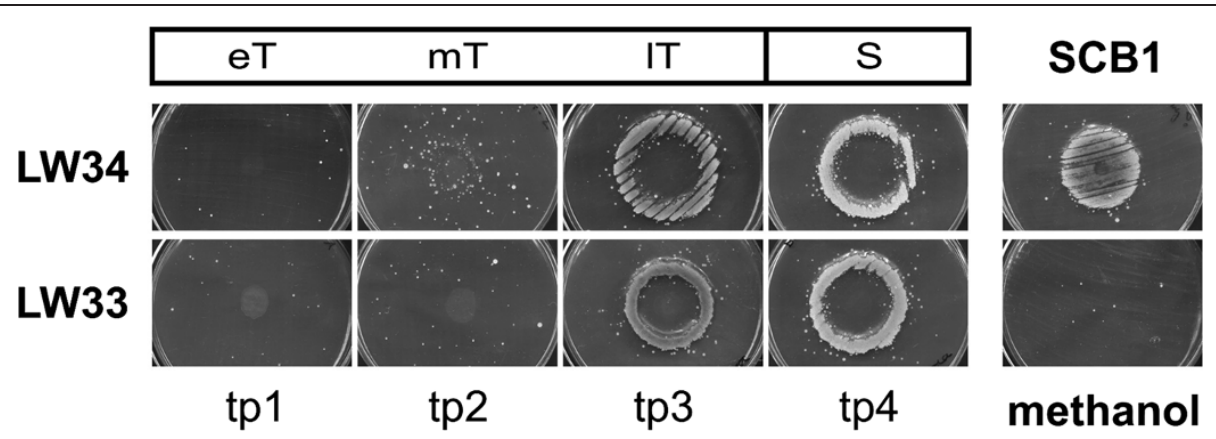

Figure 6 Y-Butyrolactone production in liquid S. coelicolor cultures using the kanamycin bioassay. The kanamycin bioassay [21] was used to detect $y$-butyrolactone production in S. coelicolor in liquid SMM at four time points (tp 1-4) during different phases of growth indicated with eT, mT, IT and S (early, mid, late transition, and stationary phase; also see Table 2, GC 2). Growth of a bioassay indicator strain on kanamycin supplemented medium is shown. Kanamycin resistance and thus growth is induced by the presence of $y$-butyrolactones. Extracts from strains LW34 and LW33, containing ScbR $\mathrm{M}_{145}$ and ScbR $\mathrm{M}_{600}$, respectively, resembled each other in the induction of growth, however, with LW34 sparse growth seems to be induced already at time point 2 and the area of growth is increased compared to LW33 with the late transition phase sample. Chemically synthesised S. coelicolor $\gamma$-butyrolactone (SCB1) was used as positive, the solvent methanol as negative control.

contrast, all LW33 extracts failed to produce a full shift. Even in the presence of a higher amount of $\mathrm{ScbR}_{\mathrm{M} 600}$ compared to ScbR $\mathrm{M}_{455}$ (LW33 in stationary and LW34 in transition phase, respectively; Figure 8B) the observed shift of $\mathrm{ScbR}_{\mathrm{M} 600}$ was weaker, suggesting that the DNA binding ability of the mutant protein in LW33 is reduced. The same results were obtained with GC 2 (data not shown).

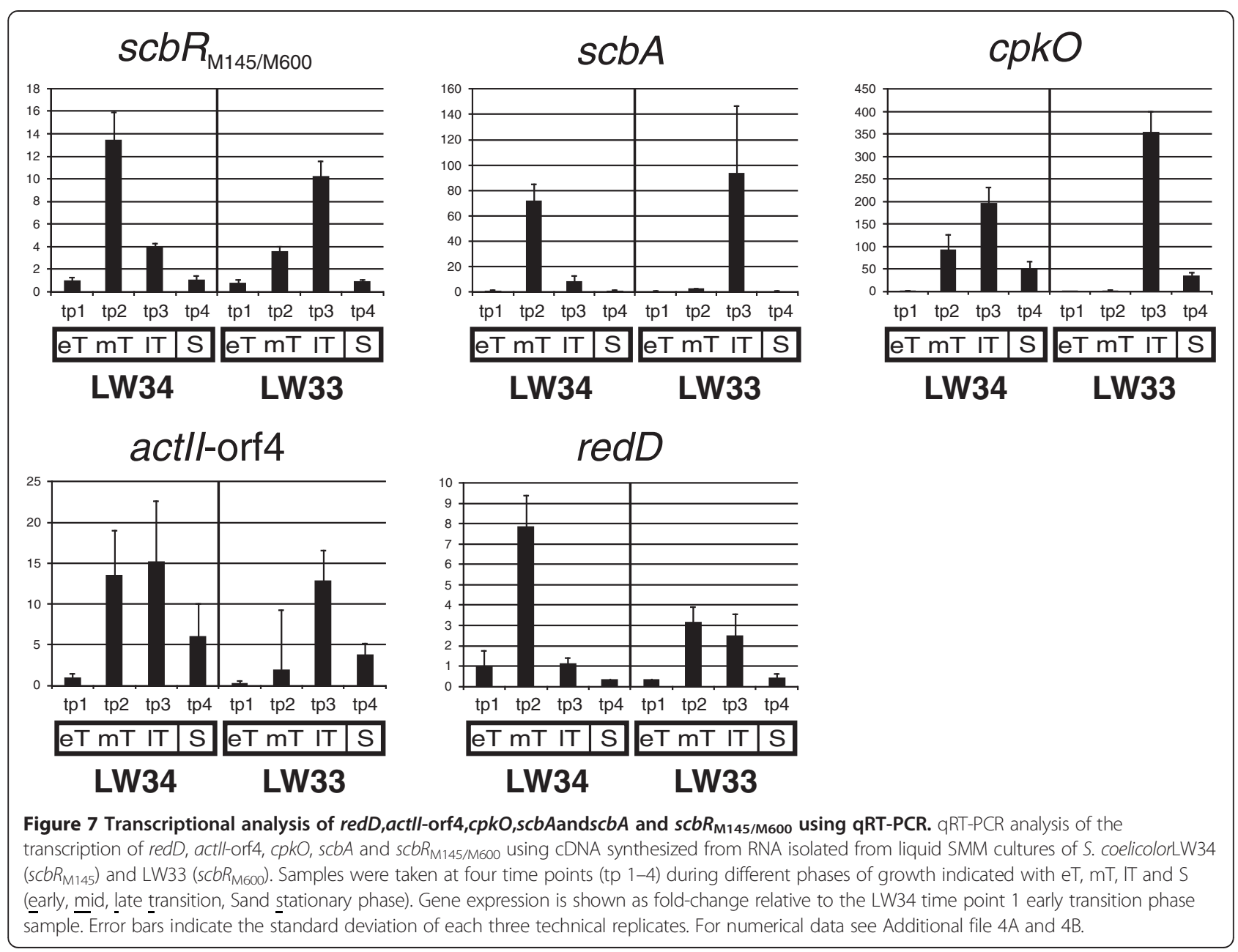




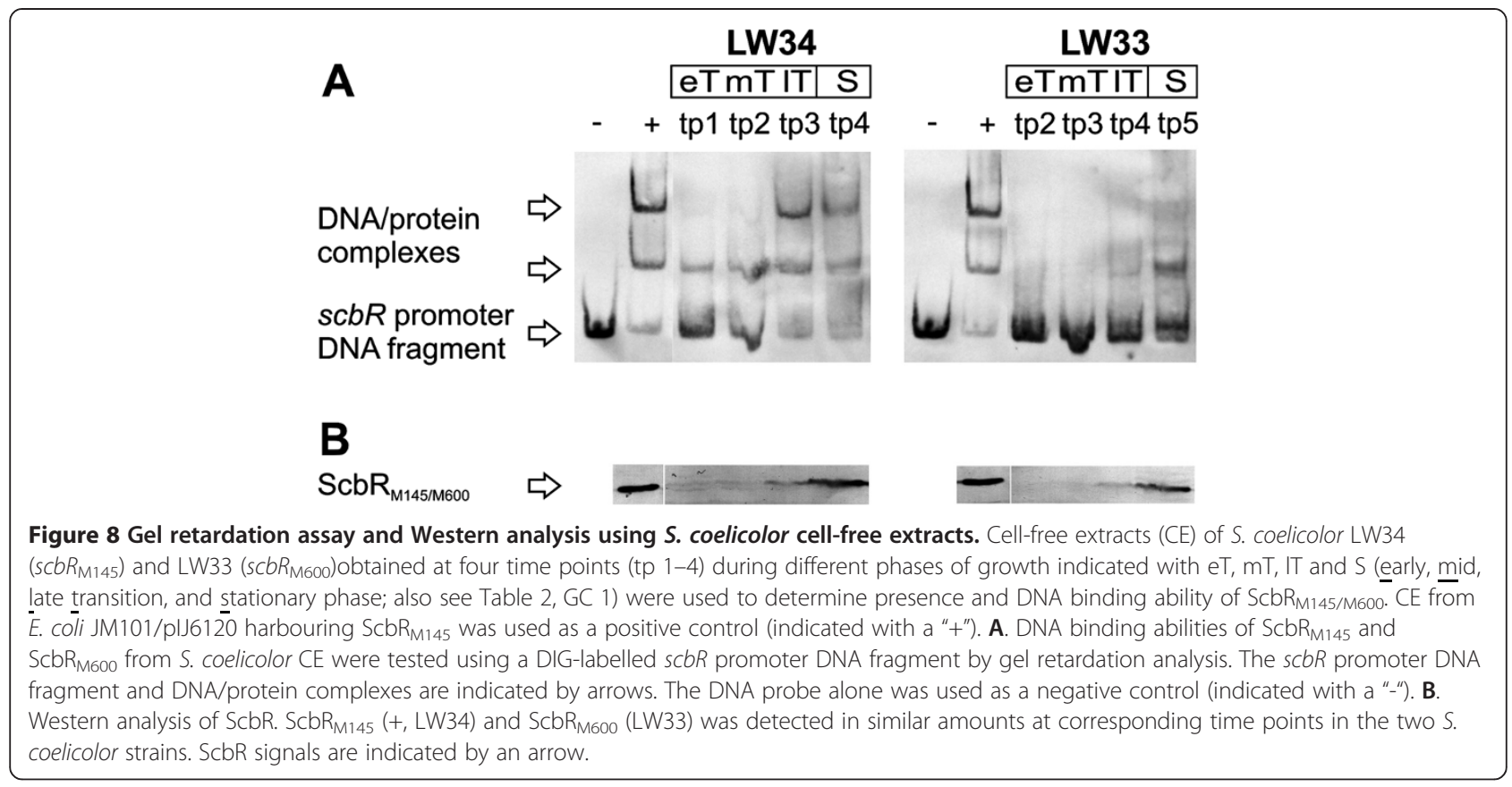

In vitro analysis using freshly prepared protein expressed in $E$. coli indicates that the DNA and $\gamma$-butyrolactone binding abilities of $\mathrm{ScbR}_{\mathrm{M} 145}$ and $\mathrm{ScbR}_{\mathrm{M} 600}$ are comparable

In vivo analysis in this study indicated that expression of mutant ScbR $_{\mathrm{M} 600}$ in $S$. coelicolor leads to altered patterns of expression of the pathway-specific regulatory genes for Red (redD) and CPK ( $c p k O)$, the $s c b A$ and $s c b R$ genes known to be controlled by ScbR in response to altered butyrolactone concentrations, and to a decreased $\mathrm{ScbR}_{\mathrm{M} 600}$ DNA binding affinity. To investigate in more detail the effect that the point mutation may have on the ability to bind both butyrolactones and its cognate DNA operator sequence, $\mathrm{ScbR}_{\mathrm{M} 145}$ and $\mathrm{ScbR}_{\mathrm{M} 600}$ were overexpressed in E. coli. Freshly prepared E. coli CE containing equal amounts (Methods; Figure 9B) of the two forms of ScbR showed comparable DNA binding abilities in gel retardation analysis (Figure 10, lanes 3 and 7 , and Figure 11A, lanes 2 and 6, respectively).

Addition of low (8 ng; Figure 10, lanes 5 and 9) and high (63 ng; Figure 10, lanes 4 and 8) amounts of the cognate $\gamma$-butyrolactone ligand SCB1 led to a partial and a complete loss of DNA binding, respectively, with both $\mathrm{ScbR}_{\mathrm{M} 145}$ and $\mathrm{ScbR}_{\mathrm{M} 600}$. Therefore, under the conditions tested, the $\gamma$-butyrolactone binding affinity of the two forms of ScbR expressed in E. coli were comparable.

\section{DNA binding ability of $\mathrm{ScbR}_{\mathrm{M} 600}$ expressed in $E$. coli is unstable}

In gel retardation analysis using $E$. coli $\mathrm{CE}$ supplemented with $4 \%(\mathrm{v} / \mathrm{v})$ glycerol, DNA binding of the mutated $\mathrm{ScbR}_{\mathrm{M} 600}$ was reduced when stored at $-20{ }^{\circ} \mathrm{C}$ for several days or weeks (data not shown). To further analyse this difference, fresh $\mathrm{CE}$ without glycerol was frozen and thawed up to three times at $-20{ }^{\circ} \mathrm{C}$ and $37{ }^{\circ} \mathrm{C}$, respectively, and the DNA binding affinity was tested by gel retardation analysis. To ensure equal amounts of protein for both $\mathrm{ScbR}_{\mathrm{M} 145}$ and $\mathrm{ScbR}_{\mathrm{M} 600}$, total protein concentrations of the $\mathrm{CE}$ were measured, and the abundance of ScbR present was confirmed by Western analysis (Figure 11B). Both proteins were active in freshly prepared and analysed CE (Figure 11A, lanes 2 and 6), but freezing and thawing of the proteins lead to a decrease (lane 7 and 8) and eventually to the loss (lane 9) of DNA binding with the mutant $\operatorname{ScbR}_{\mathrm{M} 600}$. Native $\mathrm{ScbR}_{\mathrm{M} 145}$ was not affected by the treatment (lanes 3 to 5 ). Western analysis indicated that freezing and thawing had no effect on the amount of protein detected (Figure 11B) indicating that the loss of DNA binding ability was not due to protein degradation. This suggests that compared to $\mathrm{ScbR}_{\mathrm{M} 145}$, the DNA binding ability of $\mathrm{ScbR}_{\mathrm{M} 600}$ is significantly less stable. This is also supported by the decrease in DNA binding affinity observed with the mutant protein, but not with $\mathrm{ScbR}_{\mathrm{M} 145}$, in the presence of methanol (Figure 10, lanes 6 and 10). This instability of $\operatorname{ScbR}_{M 600}$ DNA binding activity was also seen from crude extracts obtained from Streptomyces (data not shown).

\section{Discussion}

A variant form of the $\mathrm{\gamma}$-butyrolactone receptor $\mathrm{ScbR}$ in S. coelicolor

In addition to ScbR from the sequenced strain M145 $\left(S_{c b R} \mathrm{M}_{145}\right)$, a natural variant of the protein, ScbR/R120S $\left(\mathrm{ScbR}_{\mathrm{M600}}\right)$, was found in strain M600 (this study). The 

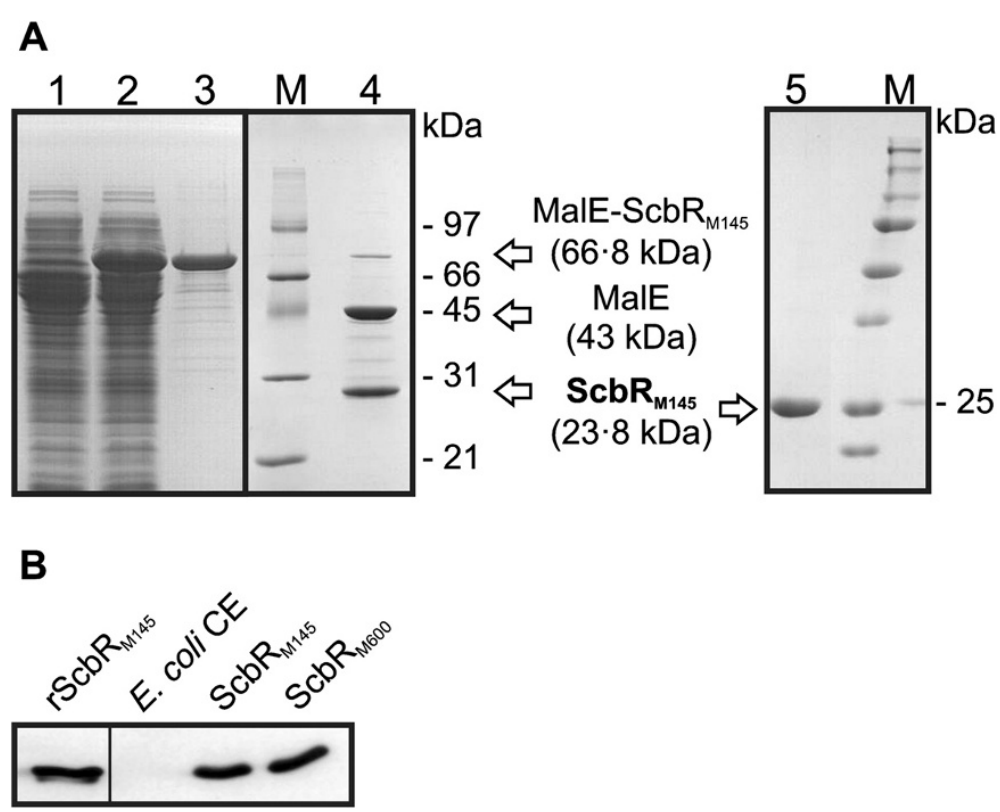

Figure 9 Heterologous expression and Western analysis of ScbR. A. Heterologous expression and purification of $\mathrm{ScbR}_{\mathrm{M} 145}$ for the creation of ScbR antibodies. Crude cell extracts from E. coli JM101 harbouring PTE88 before (lane 1) and after (lane 2) induction with $0.2 \%$ (w/V) of Lrhamnose. The MalE-ScbR $\mathrm{M}_{145}$ fusion protein present in the induced fraction was then purified with an amylose resin (lane 3). MalE-ScbR $\mathrm{M}_{145}$ was cleaved with Factor Xa to separate MalE from ScbR $\mathrm{M}_{\mathrm{M} 145}$ (lane 4). ScbR $\mathrm{R}_{\mathrm{M} 45}$ was further purified with a heparin column (lane 5). Arrows show the protein bands representing each protein. Theoretical molecular weight of MalE-ScbR $\mathrm{M}_{145}$, MalE and $\mathrm{ScbR}_{\mathrm{M} 145}$ are noted in brackets. All protein fractions were analysed on $12 \%(\mathrm{w} / \mathrm{v})$ SDS-PAGE followed by staining with Coomassie blue. M denotes for prestained protein molecular weight ladders (SM0431 (old version) (Fermentas).and Precision Plus Protein "All Blue" Standard (BioRad)). B. Heterologous expression of ScbR M145 and $\mathrm{ScbR}_{\mathbf{M 6 0 0}}$ for gel retardation assays and Western analysis of both forms of ScbR. ScbR-antibodies were generated using recombinant $\mathrm{Scb} \mathrm{R}_{\mathrm{M} 145}$ shown in (a). ScbR $R_{M 145}$ and $S c b R_{M 600}$ were expressed in E. coli JM101/plJ6120 and pTE58 harbouring $s c b R_{M 145}$ and scb $R_{M 600}$, respectively. In

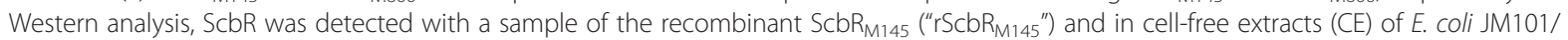

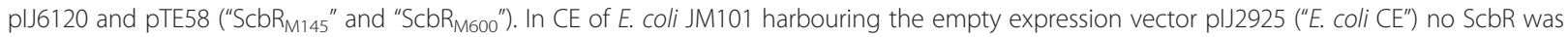
found. Comparable amounts of ScbR were detected with same amounts of total CE proteins.

underlying point mutation in the $s c b R$ gene, c358a, was also found in strain A3(2) N2, another S. coelicolor A3 (2) derivative independent from both M145 and M600 [4]. All 14 further strains tested showed the M145 genotype, including S. coelicolor W3443, the proposed progenitor of all strains described [4], and $s c b R_{\mathrm{M} 600}$ is thus regarded as a mutant variant. When mapping the known instances of this variant onto the lineage of $S$. coelicolor described by Kao and co-workers [4], our results indicate that the point mutation c358a occurred on two independent occasions, in strains M600 and A3(2) N2, perhaps indicating a selective pressure or an evolutionary relevance for this change under certain conditions.

\section{The amino acid change in $\mathrm{ScbR}_{\mathrm{M} 600}$ impairs DNA binding} in S. coelicolor

Compared to $\mathrm{ScbR}_{\mathrm{M} 145}$, DNA binding was reduced with $\mathrm{ScbR}_{\mathrm{M} 600}$ (from S. coelicolor LW34 and LW33, respectively; Figure 8). This difference is surprising since the functional localization of the altered amino acid 120 does not suggest an effect of the mutation in $s c b R_{\mathrm{M} 600}$ on the DNA binding domain of the protein. Furthermore,
Horinouchi and co-workers described the helix-turnhelix motifs of mutant ArpA/W119A as still able to bind DNA [22]. However, in the ArpA study the intensity of the shifted band observed in the absence of A-factor was noticeably weaker for the mutated ArpA/W119A than for the wild type ArpA [22]. This also implies a reduced DNA binding affinity of ArpA/W119A, and thus suggests an effect of the amino acid change W119A in ArpA similar to that observed with $S_{c b R}{ }_{M 600}$ in this study. It is interesting to note that both variants of ScbR expressed in E.coli did not have any difference in DNA binding activity. This may suggest another component in S. coelicolor is responsible for the loss of the DNA binding activity of ScbR.

The mutation in $\mathrm{ScbR}_{\mathrm{M} 600}$ has no detectable effect on $\mathrm{Y}^{-}$ butyrolactone binding

The crystal structure of a ScbR paralogue in S. coelicolor, $\mathrm{CprB}$, is regarded as representative for $\gamma$-butyrolactone receptors in streptomycetes. Functional domains for dimerization, DNA binding by helix-turn-helix motifs, and $\gamma$-butyrolactone binding have been proposed. DNA 


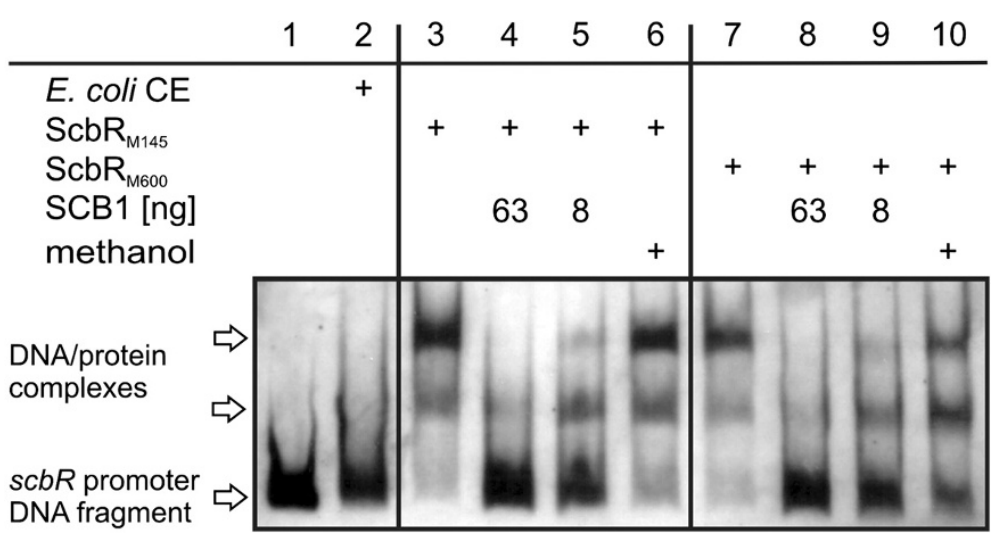

Figure $10 \mathrm{Gel}$ retardation assay using $\mathrm{ScbR}_{\mathrm{M} 145}$ and $\mathrm{ScbR}_{\mathrm{M} 600}$ from E. coli supplemented with $\mathrm{SCB} 1$. DNA and $\gamma$-butyrolactone binding abilities of $S c b R_{M 145}$ and $S c b R_{M 600}$ from E. coli cell-free extracts (CE) were tested using a DIG-labelled scbR promoter DNA fragment and the $S$. coelicolor $y$-butyrolactone SCB1 in a gel retardation assay. All samples contained the labelled DNA probe. Sample two contained CE of E. coli/ plJ2925 ("E. coli CE"), samples 3-6 and 7-10 of E. coli JM101/plJ6120 and pTE58 ("ScbR M145" and "ScbR M600"). To samples 4, 5, 8 and 9 SCB1 dissolved in methanol was added in high $(63 \mathrm{ng})$ and low $(8 \mathrm{ng})$ amounts. Samples 6 and 10 were supplemented with same volumes of pure methanol. The $s c b R$ promoter DNA fragment and DNA/protein complexes formed with $S c b R_{M 145 / M 600}$ are indicated by arrows. DNA binding abilities of the two variants of ScbR were shown to be the same in the absence and the presence of the $\gamma$-butyrolactone.

binding of CprB was shown experimentally [22], but a putative cognate $\gamma$-butyrolactone ligand has yet to be identified [14]. From the CprB amino acid sequence, amino acid 120 in ScbR is proposed to form part of a central $\alpha$-helix $(\alpha 7)$ in the regulatory region (Figure 3 ). The adjacent tryptophan residue W121 is predicted to be directly involved in forming the $\gamma$-butyrolactone binding pocket and is highly conserved among Streptomyces $\gamma$-butyrolactone receptors [14]. Mutation of the corresponding W119 in the A-factor receptor protein ArpA, a ScbR homologue in S. griseus, abolished $\gamma$ butyrolactone binding [22]. It therefore seems reasonable to suggest that a change in the amino acid residue 120 adjacent to the crucial W121 in ScbR, from a large

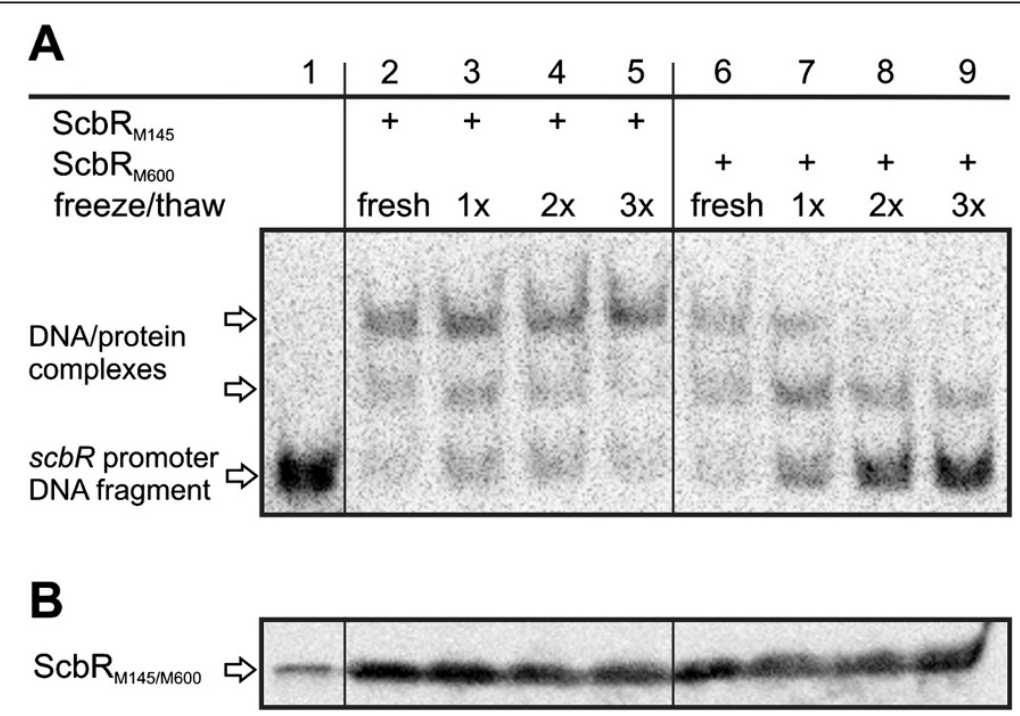

Figure $11 \mathrm{Gel}$ retardation assay and Western analysis using $\mathrm{ScbR}_{\mathrm{M} 145}$ and $\mathrm{ScbR}_{\mathrm{M} 600}$ from E. coli after freezing and thawing. A. DNA binding abilities of $\mathrm{ScbR}_{\mathrm{M} 145}$ and $\mathrm{ScbR}_{\mathrm{M} 600}$ from E. coli cell-free extracts (CE) were tested using a DIG-labelled scbR promoter DNA fragment in a gel retardation assay. All samples contained the labelled DNA probe. Samples 2-5 and 6-9 contained CE of E. coli JM101/pIJ6120 and pTE58 ("ScbR $R_{M 145}$ " and "ScbR $R_{M 600}$ "), respectively, frozen and thawed up to three times before added to the DNA probe. The scbR promoter DNA fragment and DNA/protein complexes formed with $S_{c} b R_{M 145 / M 600}$ are indicated by arrows. In contrast to $S_{c b} R_{M 145}$, DNA binding of ScbR $R_{M 600}$ was shown to be unstable under the conditions tested. B. Western analysis of ScbR. ScbR 145 was detected with a positive control sample of recombinant $\mathrm{ScbR}_{\mathrm{M} 145}$ ("rScbR $\mathrm{M}_{\mathrm{M} 45}$ ", lane 1) and in comparable amounts in all gel retardation assay samples harbouring $\mathrm{ScbR}_{\mathrm{M} 145}$ or $\mathrm{ScbR}_{\mathrm{M} 600}$ as described in A (lanes 2-9). ScbR bands are indicated by an arrow. 
(174 Da) basic arginine to a small (105 Da) neutral serine, could affect ligand binding affinity.

However, no difference in ligand binding was observed between $S_{c b R} R_{M 145}$ and $\operatorname{ScbR}_{M 600}$ (Figure 10), and it is interesting to note that ScbR amino acid 120 is not conserved among $\gamma$-butyrolactone receptor proteins. The corresponding residues in other ScbR homologues consist of members of all classes of amino acids and of hugely differing sizes (e.g., aspartate (acidic, $133 \mathrm{Da}$ ) in ArpA (S. griseus); arginine (basic, $174 \mathrm{Da}$ ) in $\mathrm{ScbR}_{\mathrm{M} 145}$; asparagine (hydrophilic, $132 \mathrm{Da}$ ) in FarA (S. lavendulae); alanine (hydrophobic, $89 \mathrm{Da}$ ) in SpbR (S. pristinaespiralis)), all adjacent to the conserved tryptophan residue [14]. The high level of variability at this position suggests residue 120 does not in fact play a significant role in $\gamma$ butyrolactone binding.

\section{$\mathrm{ScbR}_{\mathrm{M} 600}$ leads to altered gene expression and has some effects on $\boldsymbol{\gamma}$-butyrolactone production}

Expression of $s c b A$ is delayed in LW33 (Figure 7). This could be a direct effect of the impaired DNA binding ability of $S_{c b R} R_{M 600}$ since ScbR was previously shown to be necessary for $s c b A$ expression [9]. Consistently, late expression of the $\gamma$-butyrolactone synthase gene coincides with a slight delay in the production of the small signalling molecules in LW33 (Figure 6).

Also $s c b R$ expression is somewhat delayed at similar transcription levels in the presence of the M600-type protein, but not as clearly as with $s c b A$ (Figure 7). This is at first glance surprising, since a reduction in DNA binding of the auto-repressor might be expected to result in a higher or early expression of $s c b R_{\mathrm{M} 600}$. However, also in Western analysis no increase in the amount of $\mathrm{ScbR}_{\mathrm{M} 600}$ in LW33 was observed (Figure 8B). $\gamma$ butyrolactones abolish the DNA binding of ScbR and are active in $\mathrm{nM}$ concentrations (Figure 10) [9]. The small reduction in $\gamma$-butyrolactone production observed in LW33 (Figure 6) may promote binding of $S_{c b R} \mathrm{M}_{\mathrm{M} 00}$ to its target sites in vivo, counteracting the impaired binding ability of the mutant protein.

In LW33, expression of the pathway-specific regulator genes for the red and the cpk antibiotic biosynthesis gene clusters was delayed compared to that in LW34 (Figure 7 and Additional file 4AB). However expression of $s c b R, s c b A, \operatorname{redD}, c p k O$ and actII-orf4 has been shown to be highly similar in M145 and M600 in an extensive genome-wide study by Weaver and co-workers [4]. Despite these differences, antibiotic production was similar in the LW33 and LW34. Regulation of production of these antibiotics is complex and known to be affected by many additional factors [23]. The $c p k$ gene cluster, for example, was shown to be also regulated by the RapA1/A2 two-component system [24] and the global regulator DasR [25]. It appears that the changes in expression of the regulatory genes observed here are over-ridden by other control mechanisms and so do not result in any observable change in the antibiotic phenotype. Furthermore, production of other, known and unknown, secondary metabolites in $S$. coelicolor might impair the synthesis of Act, Red and yCPK, e.g. by competition for common precursors from primary metabolism. Further experiments will be needed to reveal the detailed effects of the mutation in $\mathrm{ScbR}_{\mathrm{M} 600}$ on the delicately balanced butanolide system in S. coelicolor.

Despite the somewhat impaired DNA binding ability of the mutant $S_{c b R} R_{M 600}$, our result show that strain LW33 clearly differs from a M145 $\Delta s c b R$ in-frame deletion mutant (M752). In comparison to M145, the latter strain is delayed in Red production, transcribes $s c b R$ early, and expresses cpkO early and constitutively $[9,10]$. Evidently, the single R120S amino acid change has a different impact on the $S$. coelicolor butanolide system and related secondary metabolites when compared to a complete deletion. The antibiotic production in M600 also resembles that of the M145 $\Delta s c b R$ in-frame deletion mutant (M752) where all antibiotics are produced later than M145. We have shown that the cause of this antibiotic production phenotype is not due to the point mutation in ScbR alone.

\section{Structural effect of amino acid change R120S on the DNA binding domain of $\mathrm{ScbR}_{\mathrm{M} 600}$}

DNA binding of $\mathrm{ScbR}_{\mathrm{M} 600}$ was impaired in both the natural producer $S$. coelicolor and, after harsh lowtemperature treatment, in E. coli CE. The decreased binding ability is therefore most probably not related to specific properties of the $S$. coelicolor cellular background, e.g. a hypothetical "deactivation" mechanism of the transcriptional regulator $\mathrm{ScbR}$, and it is more likely that the amino acid change is causing a structural change affecting the DNA binding domain. This is also supported by the fact that a loss of $\mathrm{ScbR}_{\mathrm{M} 600}$ DNA binding could be induced by freezing and thawing of the protein (Figure 11A), and the observation that this loss was prevented by the addition of $43 \%(\mathrm{v} / \mathrm{v})$ of glycerol (data not shown). However, modelling of both ScbR variants based on the crystal structure of the ScbR paralogue CprB [14] does not reveal an obvious destabilizing effect of the mutation R120S in $\mathrm{ScbR}_{\mathrm{M} 600}$ (data not shown; Dirk Linke, personal communication). Also, protein aggregation, specifically of the mutated $\mathrm{ScbR}_{\mathrm{M} 600}$, could cause these effects, whereas Western analysis data shown in Figure 8B and Figure 11B clearly exclude degradation of the protein as an explanation for our observations. Prediction of enzymatic cleavage using the ExPASy Peptide Cutter (Swiss Institute of Bioinformatics (SIB)) (http:// expasy.org/tools/peptidecutter/) only revealed an additional cleavage site for pepsin at pH1.3 (and not $\mathrm{pH}>2$ ) 
in ScbRM600, and the loss of one site each for Arg-C proteinase, clostripain and trypsin (data not shown).

\section{The mutation in $\mathrm{ScbR}_{\mathrm{M} 600}$ is not responsible for the absence of the protein in vegetative mycelium of strain M600}

To our surprise and in contrast to M145, ScbR $\mathrm{M}_{\mathrm{M} 600}$ was absent during vegetative growth in M600 as shown by 2D gel (Figure 1) and Western analysis (data not shown). However, $\mathrm{ScbR}_{\mathrm{M} 600}$ was present in vegetative mycelium of S. coelicolor LW33 harbouring $s c b R_{\mathrm{M} 600}$ in an M145 genetic background. The amounts were comparable to $\mathrm{ScbR}_{\mathrm{M} 145}$ in the control strain LW34. (Figure 8B) and in M145 (data not shown). This suggests that it is the M600 genetic background, and not the amino acid

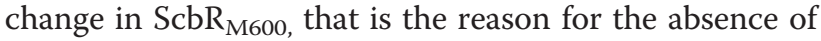
ScbR during vegetative growth of M600. Whether the altered properties of $\mathrm{ScbR}_{\mathrm{M} 600}$ are an adaptation to its synthesis in the spores of S. coelicolor M600 and/or to a putative modified function of the regulator which again might indicate evolutionary relevance remains to be determined. Detailed knowledge of the butanolide regulatory system in S. coelicolor might allow rational construction of strains with improved timing and levels of antibiotic production.

\section{Conclusions}

Among at least five paralogues in S. coelicolor (CprA, CprB, SCO6323, ScbR and ScbR2), ScbR is the only $\gamma-$ butyrolactone receptor experimentally shown to bind a cognate signalling molecule. Recently, SCO0608 (SlbR) was shown to also bind to butyrolactones with less specificity compared to ScbR, in vitro and shares similar recognition sites as ScbR. However the effect on antibiotic production is much less dramatic than that of ScbR [19,21]. Therefore ScbR still plays a key role in the S. coelicolor butanolide system involved in the regulation of the antibiotics Act and Red, and of the cpk secondary metabolite gene cluster (reviewed in [5]). We identified a variant ScbR with only one amino acid exchange in S. coelicolor M600 that is impaired in its DNA binding ability and alters the expression of the pathway-specific regulators of two antibiotic biosynthetic gene clusters. This demonstrates that the $\gamma$ butyrolactone receptor, ScbR, plays a key role in the SCB regulatory cascade and in determining the onset of the expression of the antibiotic regulatory genes. This variant was only found in two Streptomyces coelicolor strains which most likely arose in laboratory conditions. To understand how this variant was selected twice may shed light on the evolutionary diversity of signalling receptor molecules.

\section{Availability of supporting data}

The data sets supporting the results of this article are included within the article and its additional files.

\section{Methods}

\section{Bacterial strains, plasmids and cosmids}

Strains and vectors used in this study are listed in Table 1 and Additional file 5. Streptomyces was manipulated as described previously [18]. Escherichia coli was grown and transformed according to [16].

\section{Culture conditions}

For culturing E. coli, liquid LB [16] or LB agar supplemented with appropriate antibiotics was used. For genomic DNA isolation Streptomyces was grown in liquid YEME/TSB (1:1) medium as described [18]. MS medium [18] was used to harvest spores according to [18]. To determine the viable spore concentration, dilution series of spore suspensions were plated on MS or DNA medium (DNagar) [18] and the number of colony forming units was determined. DNAgar supplemented with $325 \mathrm{mM}$ (final conc.) L-Glutamic acid monosodium salt (GluDNAgar) [12] was used for determination of secondary metabolite production. For liquid Streptomyces cultures, strains were cultivated using SMM as previously described $[9,19]$. Interspecific conjugation was done as described previously [9].

\section{PCR and DNA sequencing}

Amplification of DNA by PCR [26] was done with Taq polymerase (Fermentas), ProofStart polymerase (Qiagen) or the Expand High Fidelity DNA System (Roche). DNA sequence analysis was carried out by Sequence Laboratories, Göttingen, Germany.

\section{DNA manipulation, plasmid transformation and intergeneric transfer}

Plasmid DNA isolation, restrictions and cloning experiments were carried out as described in [16]. Streptomyces was manipulated as described in [2], genomic DNA was isolated according to [27].

\section{D gel electrophoresis and MALDI-TOF mass spectrometry}

Protein extracts were prepared from typically $25 \mathrm{ml}$ culture samples according to [28] and mycelial pellets were stored at $-80{ }^{\circ} \mathrm{C}$ until use. To prepare total protein extracts from spores, spores harvested from cultures grown on MS plates [18] and stored frozen in glycerol at $-80{ }^{\circ} \mathrm{C}$ were thawed on ice, washed once with ice cold wash buffer [28], then transferred to a mortar submerged in liquid nitrogen together with an equal volume of washed glass beads (Sigma G-8893, 106 microns). The spores were then ground thoroughly 
under liquid nitrogen until an even colour and fine consistency (about $5 \mathrm{~min}$ ), and the resulting frozen powder stored at $-80{ }^{\circ} \mathrm{C}$ until use. Frozen aliquots were suspended in spore protein buffer $(50 \mathrm{mM}$ DTT, $4 \mathrm{mM}$ Pefabloc SC protease inhibitor, $40 \mathrm{mM}$ Tris $\mathrm{pH}$ 9.0, $1 \mathrm{mM}$ EDTA, $1 \mathrm{mM}$ EGTA and $2 \%$ (w/v) SDS), sonicated briefly (Sanyo Soniprep 150; 2 x 5 second bursts at amplitude 7.5 microns), and then boiled for $10 \mathrm{~min}$. After cooling, cell debris and glass beads were removed, the protein extract was cleaned up, and protein pellets were finally dissolved and stored frozen in aliquots at $-80{ }^{\circ} \mathrm{C}$ until use as described in [28]. Protein extracts from mycelia and spores were subjected to $2 \mathrm{D}$ gel electrophoresis as detailed in [28]. The strip used for the separation was an $18 \mathrm{~cm} \mathrm{pH}$ 5.5-6.7 IPG strip (Amersham Biosciences). Gels were stained with Sypro Ruby (Bio Rad) according to the manufacturer's instructions, and scanned using the Perkin-Elmer ProXPRESS proteomic imaging system using excitation and emission wavelengths of $480 \mathrm{~nm}$ and $630 \mathrm{~nm}$, respectively.

Protein spots of interest were excised from stained gels using the Investigator ProPic robot from Genomic Solutions, and identified by tryptic or chymotryptic digestion and MALDI-TOF mass spectrometry using a Micromass Q-TOF 2 mass spectrometer as previously described [28]. Identification of proteins from peptide mass fingerprint data was performed according to [28].

\section{Overexpression and purification of $\mathrm{ScbR}_{\mathrm{M} 145}$ for the generation of ScbR antibodies}

The $s c b R_{\mathrm{M} 145}$ coding sequence was amplified by PCR from the cosmid SCAH10 [29] using primers MalEScbR1 and MalE-ScbR2 (Additional file 2). The PCR product was gel-purified and ligated to pDRIVE (Qiagen), yielding pDRIVE-ScbR. This plasmid was digested with BamHI and HindIII and the fragment corresponding to $s c b R_{\mathrm{M} 145}$ was ligated to the digested BamHI/HindIII vector pTST101 [30] to allow the translational fusion of $s c b R_{\mathrm{M} 145}$ with malE, leading to pTE88. The sequence of $s c b R_{\mathrm{M} 145}$ and the translational fusion were confirmed by DNA sequencing.

E. coli JM101 was transformed with pTE88. LB with 50 $\mu \mathrm{g}$ ampicillin $\mathrm{ml}^{-1}$ was inoculated to $1 / 100$ volume with the overnight pre-culture and cells were grown at $37{ }^{\circ} \mathrm{C}$ until $\mathrm{OD}_{600}$ reached 0.5. L-rhamnose $(0.2 \%(\mathrm{w} / \mathrm{v})$ final concentration) was added for induction. After a further 2 $h$ of incubation the induced cells were harvested and washed twice with chilled Column Buffer (CB) (20 mMTris- $\mathrm{HCl}, 200 \mathrm{mM} \mathrm{NaCl}, 1 \mathrm{mM}$ EDTA), resuspended in chilled $\mathrm{CB}$ and disrupted using a French-Press. The soluble fraction containing MalE-ScbR $\mathrm{M}_{\mathrm{M} 155}$ was aliquoted and frozen at $-70{ }^{\circ} \mathrm{C}$ until use. The MalE-ScbR $\mathrm{M}_{145}$ was further purified by affinity chromatography with amylose resin (New England Biolabs) using a Bio-Logic FPLC system (Bio-Rad). After elution with CB supplemented with $10 \mathrm{mM}$ maltose, positive fractions $\left(0.5-5 \mathrm{mg} \mathrm{ml}^{-1}\right)$ detected by UV absorbance at $280 \mathrm{~nm}$ and shown to contain MalE-ScbR $\mathrm{M}_{\mathrm{M} 45}(66.4 \mathrm{kDa})$ by SDS-PAGE were pooled. ScbR $\mathrm{M}_{145}$ was cleaved from MalE by the specific protease Factor Xa $\left(10 \mu \mathrm{g} \mathrm{ml}^{-1}\right.$ final concentration, New England Biolabs). Complete cleavage was determined by SDS-PAGE and cleavage was stopped by adding $2 \mathrm{x}$ Protease Inhibitor Cocktail (Roche). ScbR $_{\text {M145 }}$ (23.8 $\mathrm{kDa}$ ) was further purified to homogeneity by affinity chromatography using a heparin column (Amersham Biosciences) coupled to the Bio-Logic FPLC system (Bio-Rad). ScbR $\mathrm{M}_{\mathrm{M} 45}$ was eluted using a continuous salt gradient (0.2-2 M NaCl in $\mathrm{CB}$ ). Positive fractions were checked on SDS-PAGE for presence and purity of $\mathrm{ScbR}_{\mathrm{M} 145}$ (Figure 9). The purified protein $(0.8 \mathrm{mg})$ was used to generate antibodies in rabbits (Eurogentec S.A., Belgium).

\section{SDS-PAGE and Western analysis}

Cell-free extracts (CE) or purified ScbR were resolved by SDS-PAGE $(12 \%(\mathrm{w} / \mathrm{v})$ resolving SDS-polyacrylamide gels) according to Laemmli's procedure [31]. Following electrophoresis, resolved bands were visualized by Coomassie brilliant blue staining. For Western analysis, proteins separated on SDS-PAGE gels were transferred to a nitrocellulose membrane by immersion or semidry blotting. Immunodetection of ScbR was carried out by using rabbit antiserum raised against $\mathrm{ScbR}_{\mathrm{M} 145}$ (this study) and horseradish peroxidase-conjugated goat anti-rabbit IgG (Bio-Rad) as a secondary antibody with Roche's CSP-Star (Figure 11B and Figure 9B) or NBT/ $\mathrm{BCIP}$ (Figure $7 \mathrm{~B}$ ) as a substrate. In the former case, Super RX Medical X-ray Film (NIF100) (Fuji film) and a Lumi-Imager F1 (Roche) (Figure 11B) or a Konica QX-150U Medical Film Processor (Figure 9B) were used for detection.

\section{Construction of the $\mathrm{ScbR}_{\mathrm{M} 600}$ expression plasmid and expression of both forms of ScbR in E. coli}

A $s c b R_{\mathrm{M} 600}$ expression vector, pTE58, was constructed as described in detail in Additional file 6A, B. Plasmid pTE58 and the $s c b R_{\mathrm{M} 145}$ expression construct pIJ6120 [9] contain the two forms of $s c b R$ with its own promoter region cloned behind the lacZ promoter in a pIJ2925 backbone. Expression constructs pTE58 and pIJ6120 were partially sequenced and differ only by the natural point mutation in $s c b R_{\mathrm{M} 600}$ (this study). E. coli JM101 was transformed with pTE58 and pIJ6120 for heterologous expression of $\mathrm{ScbR}_{\mathrm{M} 600}$ and $\mathrm{ScbR}_{\mathrm{M} 145}$ and CE was used for Western hybridisation analysis and gel retardation assays. 


\section{Cell-free extract preparation}

For E. coli cell-free extract (CE), $10 \mathrm{ml} \mathrm{LB}$ overnight cultures of E. coli JM101 harbouring pIJ2925, pIJ6120 and pTE58 were inoculated at a $1 / 100$ concentration in 50 $\mathrm{ml} \mathrm{LB}$ without glucose. Cultures were incubated at $37^{\circ} \mathrm{C}$ for $2.5 \mathrm{~h}$ or until $\mathrm{OD}_{600} 0.7-0.8$ and induced with $1 \mathrm{mM}$ (final concentration) IPTG. After $3 \mathrm{~h}$ of further incubation cells were harvested and washed twice with ice cold disruption buffer (50 mM TrisHCl pH 7.9, 1 mM EDTA pH 8.0, 1 mM DTT, 1x (final conc.) complete EDTAfree protease inhibitor (Roche)) before being resuspended in $400 \mu \mathrm{l}$ disruption buffer. For the E. coli CE used as positive control in Figure 7 the disruption buffer contained $20 \%$ (v/v; final conc.) glycerol. Cells of $100 \mu \mathrm{l}$ aliquots were collected by centrifugation, the supernatant was removed completely and the cell pellet was frozen at $-80{ }^{\circ} \mathrm{C}$. To prepare $\mathrm{CE}$, cells were resuspended in 150 or $200 \mu \mathrm{l}$ disruption buffer and were disrupted by sonication. The cell lysate was clarified by centrifugation. Total protein concentration of the supernatant was determined using the BCA Protein Assay kit (Pierce) (for Figure 10 and Figure 9B) or a NanoDrop spectrophotometer (Thermo Fisher Scientific) (for Figure 7 and Figure 11). The freshly prepared $\mathrm{CE}$ was used immediately (Figure 10 and Figure 9B (100 $\mu \mathrm{g}$ total CE protein used), and Figure $7(50 \mu \mathrm{g}))$. For Figure 11, the CE (130 $\mu \mathrm{g}$ total protein) was frozen and thawed up to three times at $-20{ }^{\circ} \mathrm{C}(15 \mathrm{~min})$ and $37{ }^{\circ} \mathrm{C}(5 \mathrm{~min})$ before being applied to gel retardation assays and Western hybridisation analysis.

For S. coelicolor CE, cells from $25 \mathrm{ml}$ samples of individual $60 \mathrm{ml}$ SMM liquid cultures were collected at different phases of growth (Table 2, GC 1). Fresh CE was prepared with all cells obtained as described for E. coli using 100,150 or $200 \mu \mathrm{l}$ disruption buffer with glycerol. $500 \mu \mathrm{g}$ total CE protein was used for Western analysis and gel retardation assays shown in Figure 8.

\section{Gel retardation analysis}

Gel retardation experiments were carried out as described previously [9] using the Roche DIG Gel Shift Kit (Roche cat No. 1635352). From a genomic DNA isolate of S. coelicolor M145, a 177 bp PCR fragment containing the ScbR binding site in the promoter region of $s c b R$ [9] was amplified using primers ETS6 and ETS10 and then was DIG-labelled according to the manufacturer's manual. For each sample approximately $0.23 \mathrm{ng}$ (Figure 11A) and $1.8 \mathrm{ng}$ (Figure 10) were used. For the results shown in Figure 8A, primer ETS10 was replaced by ETS10_DIG(5') with digoxygenin linked to the 5'-end of the primer to obtain a labelled probe directly from PCR of which $5 \mathrm{ng}$ was used in each sample (all primers are listed in Additional file 2). In some cases, 8 or $63 \mathrm{ng}$ of chemically synthesised S. coelicolor $\gamma$-butyrolactone
SCB1 was added to the mixture prior to incubation (Figure 10). For Figure 10, a Super RX Medical X-ray Film (NIF100) (Fujifilm) and a Konica QX-150U Medical Film Processor were used for detection. Pictures for Figure 8A and Figure 11A were obtained with the LumiImager F1 (Roche) and the Luminescent Image analyzer LAS-4000 (Fujifilm), respectively.

\section{Complementation of a $S$. coelicolor $M 145 \Delta s c b R$ mutant (M752) with $\mathrm{ScbR}_{\mathrm{M} 145}$ and $\mathrm{ScbR}_{\mathrm{M} 600}$ by chromosomal replacement}

$s c b R_{\mathrm{M} 145}$ and $s c b R_{\mathrm{M} 600}$ complementation vectors were constructed as described in detail in Additional file 7A, B, C, D, E. Resulting plasmids pTE212 and pTE214 contain a $2.4 \mathrm{~kb}$ fragment of $s c b R_{\mathrm{M} 600}$ and $s c b R_{\mathrm{M} 145}$ and its flanking regions, respectively, in the conjugative, nonintegrative vector pKC1132 [32] which is non-replicating in $S$. coelicolor. The $2.4 \mathrm{~kb}$ inserts were sequenced and differ only by the natural point mutation in $s c b R_{\mathrm{M} 600}$ (this study) and an additional silent point mutation, c636t, in $s c b R_{\mathrm{M} 145}$ of pTE214 with no effect on the amino acid sequence of ScbR $\mathrm{M}_{145}$. pTE212 and pTE214 were transferred into $S$. coelicolor M752 by conjugation via E. coli ET12567/pUZ8002. Single- and doublecrossover mutants were selected as described in [9], but using DNAgar for non-selective growth, yielding strains LW33 and LW34 in which the truncated $s c b R_{\mathrm{M} 145}$ region of the M145 $\Delta s c b R_{\mathrm{M} 145}$ mutant M752 was replaced by $s c b R_{\mathrm{M} 600}$ and $s c b R_{\mathrm{M} 145}$, respectively, in a M145 chromosomal background. Presence of full-length $s c b R$ genes at the right chromosomal location was confirmed by PCR using primers ETseq 3 and ETS7 and Southern analysis [18] using a PCR-generated 484 bp probe (primers scbArt1 and scbArt2 labelled with a DIG DNA labelling kit (Roche) binding to a $2.37 \mathrm{~kb}$ DNA fragment of NcoI digested chromosomal DNA in the presence of full-length $s c b R$ (Figure 4A,B). With the in-frame deletion in $s c b R_{\mathrm{M} 145}$ in $\mathrm{M} 752$, an NcoI restriction site disappears and the probe binds to a $3.2 \mathrm{~kb}$ DNA fragment. The two variants of $s c b R$ in LW33 and LW34 were confirmed by specific PCR using primers RCseq31 and scbR-M145_c358 or scbR-M600_c358a (Figure 4C) and by DNA sequence analysis of the full-length $s c b R$ PCR product shown in Figure 4C (data not shown). All primers are listed in Additional file 2.

\section{Reverse transcription and quantitative RT-PCR}

RNA was isolated as previously described [10] from LW33 and LW34 grown in duplicate in liquid SMM at different times of growth. cDNA synthesis and quantitative RT-PCR was conducted as reported in [12].Three technical replicates per gene and time point were done and $h r d B$ was used as endogenous control. All primers used for the qRT experiments are listed in Additional 
file 2. The averaged data is shown in Additional file 4A and the original study data are available as Additional file 8, data for growth curve 2 are shown in Figure 7.

\section{Detection of $\mathrm{\gamma}$-butyrolactone production in liquid $\mathrm{S}$. coelicolor cultures}

S. coelicolor LW33 and LW34 were grown in liquid $\mathrm{SMM}$ at $30{ }^{\circ} \mathrm{C}$. At four time points (Table 2, GC 2), $\gamma$ butyrolactones were extracted from the culture supernatant as described in [9] and detected by the kanamycin bioassay [21].109 spores per plate of the indicator strain were plated out for confluent lawns on DNAgar plates containing $5 \mu \mathrm{g}$ kanamycin $\mathrm{ml}^{-1}$. Each $5 \mu \mathrm{l}$ of the $\gamma$ butyrolactones extracts, as well as $125 \mathrm{ng}$ of the $\gamma$ butyrolactone SCB1 as positive control and the solvent methanol as negative control were spotted in the middle of the plates. After incubation for 3 days at $30{ }^{\circ} \mathrm{C}$ growth of the indictor strain was determined; pictures were taken from the bottom (Figure 6).

\section{Determination of secondary metabolite production}

$4 \times 10^{7}$ spores per plate of $S$. coelicolor were streaked out for a $2.5 \times 2.5 \mathrm{~cm}$ square on Glu-DNAgar, and pictures were taken from the bottom at different phases of growth to determine production of pigmented secondary metabolites (Figure 5). Antibiotic production in liquid cultures was determined as described previously [33].

\section{Additional files}

\section{Additional file 1: Data from the chymotryptic digests. \\ Additional file 2: Primers used for (qRT-)PCR experiments. \\ Additional file 3: Partial multi-sequence alignment of sequencedscbR homologues in Streptomyces. The $s c b R$ homologous coding region in various $S$. coelicolor strains (indicated on the left) and in S. lividans 1326 was (partially) amplified by PCR and the sequences were determined (see Methods). Point mutations compared to scbRM145 are indicated in bold.}

Additional file 4: Transcriptional analysis of redD, actll-orf4, cpkO, $s c b A$ and $s c b R_{\mathrm{M} 145 / \mathrm{M} 600}$ using qRT-PCR in GC 1. A. qRT-PCR analysis of the transcription of redD, actll-orf4, $c p k O, s c b A$ and $s c b R_{M 145 / M 600}$ using CDNA synthesized from RNA isolated from liquid SMM cultures of $S$.

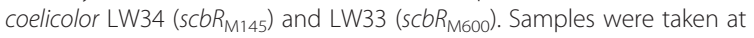
four time points (tp 1-4) during different phases of growth indicated with eT, mT, IT and S (early, mid, late transition, and stationary phase). Gene expression is shown as fold-change relative to the LW34 time point 1 early transition phase sample. Error bars indicate the standard deviation (see data in Additional file 3, GC 1). B. Numerical data from of the original qRT-PCR results.

Additional file 5: Plasmids and cosmids used in this study.

Additional file 6: Construction of the $\mathrm{ScbR}_{\mathrm{M} 600}$ expression vector pTE58. From a genomic DNA isolate of S. coelicolor strain M600, a $931 \mathrm{bp}$ PCR fragment containing the $s c b R_{M 600}$ coding sequence and the $s c b R$ promoter region was amplified using primers ETS3 and ScbR2 (Additional file 2). The PCR product was gel-purified and ligated to pDRIVE (Qiagen), yielding pTE51 of which the insert contains not only the natural mutation $c 358 \mathrm{a}$ in $s c b R_{\mathrm{M} 600}$, but also additional mutations: a $30 \mathrm{~g}$ in $s c b A$ is located in the promoter region of $s c b R$, and nucleotide change t587a in the coding sequence of $s c b R_{M 600}$, respectively. The point mutation t587a leads to an amino acid change, D196V, in ScbR $\mathrm{M}_{\mathbf{1}}$ (data not shown). A 948 bp pTE51/ECORI scbR $R_{\text {M600 }}$ fragment was cloned into the pUC18 derivate plJ2925 to gain pTE53 containing all three described mutations (A). A 844 bp pTE53/Pstl fragment containing the $s c b R$ promoter region and nucleotides 1-535 of the $s c b R_{M 600}$ coding region was ligated into a 3103 bp plJ6120/Pstl vector fragment [9] containing nucleotides $536-648$ of the $s c b R_{M 145}$ coding region, yielding pTE56. Partial sequence analysis of PTE56 revealed only the $s c b R$ promoter mutation $\mathrm{a} 30 \mathrm{~g}$ in $s c b A$ and the expected coding sequence mutation c358a of $s c b R_{M 600}$. A 851 bp pTE56/Sacll fragment containing nucleotides 54-304 of scbR $R_{M 600}$ was cloned into a 3047 bp plJ6120/Sacll vector fragment containing the $s c b R$ promoter region and nucleotides 1-53 and 305-648 of the $s c b R_{M 145}$ coding sequence, yielding PTE58 with $s c b R_{M 600}$ and the $s c b R$ promoter region without additional undesired mutations in the same orientation as the IPTG-inducible E. coli lacZ promoter (B). The $s c b R_{M 145}$ expression construct plJ6120 [9] and pTE58 differ only by the natural mutation, $c 358 \mathrm{a}$, in $s c b R_{M 600}$ and were used for the heterologous expression of $\mathrm{ScbR}_{\mathrm{M} 145}$ and $\mathrm{ScbR}_{\mathrm{M} 600}$ in E. coli. Linear DNA fragments are named and a scale is given with indicated base pair (bp) units. Plasmids are named and represented by black circles. Genes are indicated by dark arrows and labelled with gene names. For incomplete genes, the missing part is indicated by an apostrophe at the beginning or the end of the gene name. Antibiotic resistance genes are abbreviated with "amp" for ampicillin and "apra" for apramycin. "lacZ" denotes for the LacZ apeptide coding sequence. The position of the described mutations is indicated by labelled grey boxes on the scales and in the plasmid maps; relevant restriction sites are shown with enzyme names. Thick black lines with arrows indicate ligation events; big black arrows with enzyme names indicate corresponding restriction steps.

Additional file 7: Construction of the complementation vectors pTE212 and pTE214. From genomic DNA isolates of S. coelicolor strains M145 and M600, a 2406 bp PCR fragment containing the $s c b R_{M 145 / M 600}$ coding sequence and flanking regions was amplified using primers BamRCseq31enh and BamETseq1 (Additional file 2). PCR products were gel-purified and ligated to pGEM-T EASY (Promega), yielding pTE63 harbouring $s c b R_{\text {M145 }}(\mathbf{A})$, and pTE64 (B) and pTE203 (C) harbouring $s c b R_{\mathrm{M} 600}$. The inserts of the plasmids were sequenced and pTE63 was found to contain mutations in $s c b R_{M 145}$ (silent mutation $c 636 t$ ) and $s c b A$ (c308t leading to A103V). pTE64 contains a mutation in scbA (t77c leading to M26T), and PTE203 in scbB (c644t leading to A215V). Two 1405 bp pTE203/Pstl fragments were introduced by tandem integration into a 4016 bp pTE64/Pstl vector fragment to give pTE211, which is pGEM-T EASY with a $2394 \mathrm{bp} \mathrm{BamHI} s c b R_{M 600}$ fragment without any additional mutations and an additional $1.4 \mathrm{~kb} \mathrm{BamHI}$ fragment. The $2394 \mathrm{bp}$ PTE211/BamHI fragment was cloned into pKC1132 to give PTE212 (D). A 1269 bp pTE63/Ncol fragment containing the silent mutation c636t in $s c b R_{M 145}$ was cloned into a 4152 bp pTE211/Ncol vector fragment to give pTE213, which is pGEM-T EASY with a $2394 \mathrm{bp} \mathrm{BamHI} \mathrm{scbR}$ M145 fragment with only the silent mutation. The $2394 \mathrm{bp}$ pTE213/BamHI fragment was cloned into pKC1132 to give PTE214 (E). Linear DNA fragments are named and a scale is given with indicated base pair (bp) units. Plasmids are named and represented by black circles. Genes are indicated by dark arrows and labelled with gene names. For incomplete genes, the missing part is indicated by an apostrophe at the beginning or the end of the gene name. The ampicillin antibiotic resistance gene is abbreviated with "amp". The position of the described mutations is indicated by labelled grey boxes on the scales and in the plasmid maps; relevant restriction sites are shown with enzyme names. Thick black lines with arrows indicate ligation events; big black arrows with enzyme names indicate corresponding restriction steps.

Additional file 8: Excel file containing original qRT-PCR results.

\section{Competing interests}

None of the authors have a competing interest.

\section{Authors' contributions}

$M G, A H, R B$, and PP conducted the experiments. $A H$ and $E T$ designed the experiments. MG, $\mathrm{AH}$ and $\mathrm{ET}$ analysed the results and wrote the manuscript. All authors read and approved the final manuscript. 


\section{Acknowledgements}

We thank D. Weaver and C. M. Kao for the provision of numerous $S$. coelicolor strains. We thank Atze van der Pol for technical assistance. MG was funded by the EU FP6 programme ActinoGEN (Project No. FP6 - 5224), RB was funded by Deutsche Forschungsgemeinschaft (TA428/2-1) DFG-Forschergruppe 449 'Bacterial cell envelope'. ET was supported by a Rosalind Franklin Fellowship from the University of Groningen.

\section{Author details}

'Department of Microbial Physiology, Groningen Biomolecular Sciences and Biotechnology Institute, University of Groningen, Nijenborgh 7, 9747 AG Groningen, The Netherlands. ${ }^{2}$ Present address: Life Technologies, Frankfurter Str. 129b, 64293 Darmstadt, Germany. ${ }^{3}$ Department of Molecular Microbiology, John Innes Centre, Norwich Research Park, Colney, Norwich NR4 7UH, UK. ${ }^{4}$ Present address: Department of Biochemistry, New Building (Sanger), 80 Tennis Court Road, Old Addenbrooke's Site, Cambridge CB2 1GA, UK. ${ }^{5}$ Present address: Équipe de Biologie Moléculaire Marine - PROTEE, Université du Sud Toulon-Var, BP 20132, Avenue de l'Université, 83957 La Garde Cedex, France. ${ }^{6}$ Present address: Department of Enzymology, Groningen Biomolecular Sciences and Biotechnology Institute, University of Groningen, Nijenborgh 4, 9747 AG Groningen, The Netherlands.

Received: 24 February 2012 Accepted: 27 July 2012

Published: 27 July 2012

\section{References}

1. Champness W: Actinomycete development, antibiotic production and phylogeny: questions and challanges. In Prokaryotic Development. Edited by Brun YV, Skimkets LJ. Washington, DC, USA: ASM Press; 2000:11-31.

2. Miyadoh S: Research on antibiotic screening in Japan over the ILastdecade: A producing microorganism approach. Actinomycetologica 1993, 7:100-106

3. Bentley SD, Chater KF, Cerdeno-Tarraga AM, Challis GL, Thomson NR, James KD, Harris DE, Quail MA, Kieser H, Harper D, Bateman A, Brown S, Chandra G, Chen CW, Collins M, Cronin A, Fraser A, Goble A, Hidalgo J, Hornsby T, Howarth S, Huang CH, Kieser T, Larke L, Murphy L, Oliver K, O'Neil S, Rabbinowitsch E, Rajandream MA, Rutherford K, Rutter S, Seeger K, Saunders D, Sharp S, Squares R, Squares S, Taylor K, Warren T, Wietzorrek A, Woodward J, Barrell BG, Parkhill J, Hopwood DA: Complete genome sequence of the model actinomycete Streptomyces coelicolor A3(2). Nature 2002, 417:141-147.

4. Weaver D, Karoonuthaisiri N, Tsai HH, Huang CH, Ho ML, Gai S, Patel KG, Huang J, Cohen SN, Hopwood DA, Chen CW, Kao CM: Genome plasticity in Streptomyces: identification of $1 \mathrm{Mb}$ TIRs in the S. coelicolor A3(2) chromosome. Mol Microbiol 2004, 51:1535-1550.

5. Takano E: Gamma-butyrolactones: Streptomyces signalling molecules regulating antibiotic production and differentiation. CurrOpin Microbiol 2006, 9:287-294.

6. Horinouchi S, Beppu T: Regulation of secondary metabolism and cell differentiation in Streptomyces: A-factor as a microbial hormone and the AfsR protein as a component of a two-component regulatory system. Gene 1992, 115:167-172.

7. Horinouchi S: A microbial hormone, A-factor, as a master switch for morphological differentiation and secondary metabolism inStreptomyces griseus. Front Biosci 2002, 7:d2045-d2057.

8. Takano E, Nihira T, Hara Y, Jones JJ, Gershater CJ, Yamada Y, Bibb M: Purification and structural determination of SCB1, a gammabutyrolactone that elicits antibiotic production in Streptomyces coelicolorA3(2). J BiolChem 2000, 275:11010-11016.

9. Takano E, Chakraburtty R, Nihira T, Yamada Y, Bibb MJ: A complex role for the gamma-butyrolactone $\mathrm{SCB} 1$ in regulating antibiotic production in Streptomyces coelicolorA3(2). MolMicrobiol 2001, 41:1015-1028.

10. Takano E, Kinoshita H, Mersinias V, Bucca G, Hotchkiss G, Nihira T, Smith CP Bibb M, Wohlleben W, Chater K: A bacterial hormone (the SCB1) directly controls the expression of a pathway-specific regulatory gene in the cryptic Type I polyketide biosynthetic gene cluster ofStreptomyces coelicolor. MolMicrobiol 2005, 56:465-479.
11. Pawlik K, Kotowska M, Chater KF, Kuczek K, Takano E: A cryptic Type I polyketide synthase (cpk) gene cluster inStreptomyces coelicolorA3(2). Arch Microbiol 2007, 187:87-99.

12. Gottelt M, Kol S, Gomez-Escribano JP, Bibb M, Takano E: Deletion of a regulatory gene within the cpk gene cluster reveals novel antibacterial activity inStreptomyces coelicolor A3(2). Microbiology 2010, 156:2343-2353.

13. Ramos JL, Martinez-Bueno M, Molina-Henares AJ, Teran W, Watanabe K, Zhang X, Gallegos MT, Brennan R, Tobes R: The TetR family of transcriptional repressors. Microbiol Mol Biol Rev 2005, 69:326-356.

14. Natsume R, Ohnishi Y, Senda T, Horinouchi S: Crystal structure of a gamma-butyrolactoneautoregulator receptor protein inStreptomyces coelicolorA3(2). J MolBiol 2004, 336:409-419.

15. Finley EL, Dillon J, Crouch RK, Schey KL: Identification of tryptophan oxidation products in bovine alpha-crystallin. Protein Sci 1998, 7:2391-2397.

16. Sambrook J, Russell DW: Molecular cloning: a laboratory manual. New York: Cold Spring Harbor Laboratory Press; 2001

17. MacNeil DJ, Occi JL, Gewain KM, MacNeil T, Gibbons PH, Ruby CL, Danis SJ: Complex organization of the Streptomyces avermitilis genes encoding the avermectin polyketide synthase. Gene 1992, 115:1 19-125.

18. Kieser T, Bibb MJ, Buttner MJ, Chater KF, Hopwood DA: Practical Streptomyces Genetics. Norwich, United Kingdom: John Innes Foundation; 2000.

19. Yang YH, Song E, Kim JN, Lee BR, Kim EJ, Park SH, Kim WS, Park HY, Jeon JM, Rajesh T, Kim YG, Kim BG: Characterization of a new ScbR-like $\gamma^{-}$ butyrolactone binding regulator (SlbR) in Streptomyces coelicolor. App/Microbiol Biotechnol 2012, doi:10.1007/s00253-011-3803-4.

20. Chakraburtty R, Bibb M: The ppGppsynthetase gene (relA) of Streptomyces coelicolor A3(2) plays a conditional role in antibiotic production and morphological differentiation. J Bacteriol 1997, 179:5854-5861.

21. Hsiao NH, Nakayama S, Merlo ME, de Vries M, Bunet R, Kitani S, Nihira T, Takano E: Analysis of two additional signaling molecules inStreptomyces coelicolorand the development of a butyrolactone-specific reporter system. ChemBiol 2009, 16:951-960.

22. Sugiyama M, Onaka $H$, Nakagawa T, Horinouchi S: Site-directed mutagenesis of the A-factor receptor protein: Val-41 important for DNA-binding and Trp-119 important for ligand-binding. Gene 1998, 222:133-144.

23. Bibb MJ: Regulation of secondary metabolism in streptomycetes. CurrOpin Microbiol 2005, 8:208-215.

24. Lu Y, Wang W, Shu D, Zhang W, Chen L, Qin Z, Yang S, Jiang W: Characterization of a novel two-component regulatory system involved in the regulation of both actinorhodin and a type I polyketide in Streptomyces coelicolor. ApplMicrobiol Biotechnol 2007, 77:625-635.

25. Rigali S, Titgemeyer F, Barends S, Mulder S, Thomae AW, Hopwood DA, van Wezel GP: Feast or famine: the global regulator DasR links nutrient stress to antibiotic production byStreptomyces. EMBO Rep 2008, 9:670-675.

26. Mullis K, Faloona F, Scharf S, Saiki R, Horn G, Erlich H: Specific enzymatic amplification of DNA in vitro: the polymerase chain reaction. Cold Spring HarbSymp Quant Biol 1986, 51(Pt 1):263-273.

27. Leblond P, Fischer G, Francou FX, Berger F, Guerineau M, Decaris B: The unstable region of Streptomyces ambofaciens includes $210 \mathrm{~kb}$ terminal inverted repeats flanking the extremities of the linear chromosomal DNA. MolMicrobiol 1996, 19:261-271.

28. Hesketh AR, Chandra G, Shaw AD, Rowland JJ, Kell DB, Bibb MJ, Chater KF: Primary and secondary metabolism, and post-translational protein modifications, as portrayed by proteomic analysis ofStreptomyces coelicolor. MolMicrobiol 2002, 46:917-932.

29. Redenbach M, Kieser HM, Denapaite D, Eichner A, Cullum J, Kinashi H, Hopwood DA: A set of ordered cosmids and a detailed genetic and physical map for the $8 \mathrm{MbStreptomyces} \mathrm{coelicolorA3(2)} \mathrm{chromosome.}$ MolMicrobiol 1996, 21:77-96.

30. Motejadded $\mathrm{H}$, Altenbuchner J: Construction of a dual-tag system for gene expression, protein affinity purification and fusion protein processing. BiotechnolLett 2009, 31:543-549. 
31. Laemmli UK: Cleavage of structural proteins during the assembly of the head of bacteriophage T4. Nature 1970, 227:680-685.

32. Bierman M, Logan R, O'Brien K, Seno ET, Rao RN, Schoner BE: Plasmid cloning vectors for the conjugal transfer of DNA fromEscherichia colitoStreptomyces spp. Gene 1992, 116:43-49.

33. Strauch E, Takano E, Baylis HA, Bibb MJ: The stringent response inStreptomyces coelicolorA3(2). MolMicrobiol 1991, 5:289-298.

doi:10.1186/1756-0500-5-379

Cite this article as: Gottelt et al.: Characterisation of a natural variant of the $\gamma$-butyrolactone signalling receptor. BMC Research Notes 2012 5:379.

\section{Submit your next manuscript to BioMed Central and take full advantage of:}

- Convenient online submission

- Thorough peer review

- No space constraints or color figure charges

- Immediate publication on acceptance

- Inclusion in PubMed, CAS, Scopus and Google Scholar

- Research which is freely available for redistribution 